\title{
Existence and stability in the $\alpha$-norm for nonlinear neutral partial differential equations with finite delay
}

\author{
TAoufik Chitioui, \\ Université de Sfax, \\ Faculté des Sciences de Sfax, \\ Sfax, Tunisie. \\ chtioui.taoufik@yahoo.fr
}

\author{
KHALIL EzzINBi, \\ Caddy Ayyad University, \\ Université Cadi Ayyad, \\ Faculté des Sciences Semlalia, \\ BP 2390, Marrakech, Morocco, \\ ezzinbi@gmail.com
}

\author{
AMOR REBEY \\ Université de Kairouan \\ Institut Supérieur des \\ Mathématiques Appliquées et \\ de l'Informatique, \\ Tunisie. \\ ezzinbi@gmail.com
}

\begin{abstract}
In this work, we study the existence, regularity and stability of solutions for some nonlinear class of partial neutral functional differential equations. We assume that the linear part generates a compact analytic semigroup on a Banach space $X$, the delayed part is assumed to be continuous with respect to the fractional power of the generator. For illustration, some application is provided for some model with diffusion and nonlinearity in the gradient.
\end{abstract}

\section{RESUMEN}

En este trabajo estudiamos la existencia, regularidad y estabilidad de soluciones para una clase de ecuaciones diferenciales parciales funcionales neutrales. Asumimos que la parte lineal genera un semigrupo compacto analítico en un espacio de Banach X, la parte retardada se asume continua respecto de la potencia fraccional del generador. Como ejemplo, se muestra una aplicación para un modelo con difusión y no linealidad en el gradiente.

Keywords and Phrases: Neutal equation; Analytic semigroup; Fractional power; Mild solution; Strict solution.

2010 AMS Mathematics Subject Classification: 


\section{Introduction}

In this paper, we study the existence, regularity and stability of solutions in the $\alpha$-norm for partial differential equations with finite delay. The following model provides an example of such a situation

$$
\left\{\begin{array}{r}
\frac{\partial}{\partial t}\left[v(t, x)-q v(t-r, x)+g\left(\frac{\partial}{\partial x} v(t-r, x)\right)\right]=\frac{\partial^{2}}{\partial x^{2}}[v(t, x)-q v(t-r, x) \\
\left.+g\left(\frac{\partial}{\partial x} v(t-r, x)\right)\right]+f\left(v(t-r, x), \frac{\partial}{\partial x}[v(t, x)-q v(t-r, x)]\right) \\
\text { for } t \geq 0 \text { and } x \in[0, \pi], \\
v(t, 0)-q v(t-r, 0)=v(t, \pi)-q v(t-r, \pi)=0 \text { for } t \geq 0, \\
v(\theta, x)=v_{0}(\theta, x) \text { for }-r \leq \theta \leq 0 \text { and } x \in[0, \pi],
\end{array}\right.
$$

where $q, r$ are positive constants, the initial data $v_{0}$ is given function and $f, g$ are continuous functions. The previous system can be written as a neutral partial differential equation of the following form

$$
\left\{\begin{array}{l}
\frac{d}{d t}\left[x(t)-G\left(t, x_{t}\right)\right]=-A\left[x(t)-G\left(t, x_{t}\right)\right]+F\left(t, x_{t}\right) \quad \text { for } t \geq 0, \\
x_{0}=\varphi \in C_{\alpha},
\end{array}\right.
$$

where $-A$ generates an analytic semigroup $(T(t))_{t \geqslant 0}$ on a Banach space $X, C_{\alpha}:=C\left([-r, 0], D\left(A^{\alpha}\right)\right), r>$ 0 , and $0<\alpha<1$, denotes the space of continuous functions from $[-r, 0]$ into $\mathrm{D}\left(A^{\alpha}\right)$, and the operator $A^{\alpha}$ is the fractional $\alpha$-power of $A$. This operator $\left(A^{\alpha}, D\left(A^{\alpha}\right)\right)$ will be describe later. For $x \in C\left([-r, b], D\left(A^{\alpha}\right)\right), b>0$, and $t \in[0, b], x_{t}$ denotes, as usual, the element of $C_{\alpha}$ defined by $x_{t}(\theta)=x(t+\theta)$ for $\theta \in[-r, 0] . G$ and $F$ are continuous functions from $\mathbb{R}_{+} \times C_{\alpha}$ with values respectively in $X_{\alpha}$ and $X$.

This work was motivated by [4, 18. In [4] the authors have developed a basic theory of partial neutral functional differential equations in fractional power spaces, they proved the existence and regularity of the solution of Eq. (2), but only in the case where $G: C_{\alpha} \rightarrow D\left(A^{\alpha}\right)$ is a bounded linear operator. They considered the following neutral partial differential equation

$$
\begin{cases}\frac{\mathrm{d}}{\mathrm{dt}} \mathrm{D}\left(x_{\mathrm{t}}\right) & =-\mathrm{AD}\left(x_{\mathrm{t}}\right)+\mathrm{F}\left(x_{\mathrm{t}}\right) \quad \text { for } \mathrm{t} \geq 0, \\ x_{0} & =\varphi \in \mathrm{C}_{\alpha},\end{cases}
$$

where $\mathrm{D}$ is a bounded linear operator from $\mathrm{C}_{\alpha}$ into $\mathrm{X}_{\alpha}$ defined by $\mathrm{D} \varphi=\varphi(0)-\mathrm{D}_{0} \varphi$, for $\varphi \in \mathrm{C}_{\alpha}$, where $D_{0}$ is a bounded linear operator given by:

$$
\mathrm{D}_{0} \varphi=\int_{-r}^{0} \mathrm{~d} \eta(\theta) \varphi(\theta) \quad \text { for } \varphi \in \mathrm{C}_{\alpha}
$$

and $\eta:[-r, 0] \rightarrow \mathcal{L}\left(X_{\alpha}\right)$ is of bounded variation and non-atomic at zero. That is

$$
\operatorname{var}_{[-\varepsilon, 0]}(\eta) \rightarrow 0 \quad \text { as } \varepsilon \rightarrow 0
$$


Which $F$ is a globally Lipschitz continuous mapping from $C_{\alpha}$ into $D\left(A^{\alpha}\right)$, and if $x \in D\left(A^{\alpha}\right)$ and $\theta \in[-r, 0]$ then $\eta(\theta) x \in D\left(A^{\alpha}\right)$ and $A^{\alpha} \eta(\theta) x=\eta(\theta) A^{\alpha} x$.

It is well known, that if the phase space $C_{\alpha}$ is the space of all continuous functions from $[-r, 0]$ into $X$ (i.e. $\alpha=0$ ), Equation (3) has been studied by several authors. For more details, we refer to the book of $\mathrm{Wu}$ [29]. For example, $\mathrm{Wu}$ and Xia considered in [30] a system of partial neutral functional differential-difference equations defined on the unit circle $S^{1}$, which is a model for a continuous circular array of resistively coupled transmission lines with mixed initial boundary conditions. They obtained equations of the form

$$
\frac{\partial}{\partial t}[x(., t)-q x(., t-r)]=K \frac{\partial^{2}}{\partial \xi^{2}}[x(., t)-q x(., t-r)]+f\left(x_{t}\right) \quad \text { for } t \geq 0,
$$

where $\xi \in \mathrm{S}^{1}, \mathrm{~K}$ a positive constant and $0 \leq \mathrm{q}<1$. The space of initial data was chosen to be $\mathrm{C}\left([-\mathrm{r}, 0] ; \mathrm{H}^{1}\left(\mathrm{~S}^{1}\right)\right)$. Motivated by this work, Hale presented, in [19, 20, the basic theory of existence and uniqueness, and properties of the solution operator, as well as Hopf bifurcation and conditions for the stability and instability of periodic orbits for a more general class of PNFDE on the unit circle $S^{1}$. For the sake of comparison, let us briefly restate the equations considered by Hale in [19, 20]. If $\varphi \in \mathrm{C}\left([-r, 0] ; \mathrm{H}^{1}\left(S^{1}\right)\right)$, we write it as $\varphi(\xi, \theta)$ for $\xi \in S^{1}$ and $\theta \in[-r, 0]$. For any function $\tilde{f} \in C^{k+1}(C([-r, 0] ; \mathbb{R}) ; \mathbb{R}), k \geq 1$, we let $f \in C^{k+1}\left(C\left([-r, 0] ; H^{1}\left(S^{1}\right)\right) ; L^{2}\left(S^{1}\right)\right)$ be defined by $f(\varphi)(\xi)=\tilde{f}(\varphi(\xi,)),. \xi \in S^{1}$. Let $\tilde{D} \in \mathcal{L}(C([-r, 0] ; \mathbb{R}) ; \mathbb{R})$ be defined by

$$
\left\{\begin{array}{l}
\tilde{D} \psi=\psi(0)-\tilde{g}(\psi), \\
\tilde{g}(\psi)=\int_{-r}^{0} d \eta(\theta) \psi(\theta),
\end{array}\right.
$$

where $\eta$ is of bounded variation and non-atomic at 0 .

We define $\mathrm{D} \in \mathcal{L}\left(\mathrm{C}\left([-\mathrm{r}, 0] ; \mathrm{H}^{1}\left(\mathrm{~S}^{1}\right)\right) ; \mathrm{H}^{1}\left(\mathrm{~S}^{1}\right)\right)$ as

$$
\mathrm{D}(\varphi)(\xi)=\tilde{\mathrm{D}}(\varphi(\xi, .)) \quad \text { for } \xi \in \mathrm{S}^{1} .
$$

Hale considered, in 19, 20, PNFDE of the form

$$
\frac{\partial}{\partial t} D x_{t}=K \frac{\partial^{2}}{\partial \xi^{2}} D x_{t}+f\left(x_{t}\right) \text { for } t \geq 0
$$

with $\mathrm{C}\left([-\mathrm{r}, 0] ; \mathrm{H}^{1}\left(\mathrm{~S}^{1}\right)\right)$ as the space of initial data. He considered the Laplace operator $A_{0}=K \frac{\partial^{2}}{\partial \xi^{2}}$ with domain $H^{2}\left(S^{1}\right)$, which yields an operator generating an analytic semigroup. In [1, 2, 3], authors considered a natural generalization of the work of Hale [19, 20. We extended the study to the case when the linear part of PNFDE is non-densely defined Hille-Yosida operator. In 27], Travis and Webb investigated the local existence of mild solutions and strong solutions of Eq. (2) with respect to the $\alpha$-norm, but in the particular case when $G(.,)=$.0 . The existence of strong solutions is considered when $F$ is locally Hölder continuous in both of its variables, also in [26, they studied the existence and regularity of mild solution when F is Lipschitz continuous with 
the X-norm.

Here, we assume that $G$ is a nonlinear function and is defined in a smaller space than $C_{X}$, that is $C_{\alpha}$ for some $0<\alpha<1$, the space of continuous function from $[-r, 0]$ into $X_{\alpha}$, which will be specified later. We prove the existence of the mild and strict solution.

This paper is organized as follows. In Section 2, we recall some preliminary results about analytic semigroups and fractional power associated to its generator and the definition of the measure of noncompactness. After that, we start to prove the existence and uniqueness of mild solutions in the $\alpha$-norm for Eq. (2). In Section 3, we study the regularity of solution, we give sufficient conditions to get the existence of the strict solutions. In Section 4, we state some properties of the solution operator associated to the autonomous case of Eq. (2). Also, we investigate the stability near an equilibrium. Mainly, we prove that the equilibrium of the solution semigroup associated to the autonomous case is locally exponentially stable when its linearized solution semigroup around this equilibrium is exponentially stable. Finally, to illustrate our results, we give in Section 5 an application to a reaction diffusion equation.

\section{Existence of mild solutions}

Let $(X,\|\cdot\|)$ be a Banach space, and $\alpha$ be a constant such that $0<\alpha<1$ and $-A$ be the infinitesimal generator of a bounded analytic semigroup of linear operator $(T(t))_{t \geq 0}$ on $X$. We assume without loss of generality that $0 \in \rho(A)$. Note that if the assumption $0 \in \rho(A)$ is not satisfied, one can substitute the operator $A$ by the operator $(A-\sigma I)$ with $\sigma$ large enough such that $0 \in \rho(A-\sigma)$. This allows us to define the fractional power $A^{\alpha}$ for $0<\alpha<1$, as a closed linear invertible operator with domain $D\left(A^{\alpha}\right)$ dense in $X$. The closeness of $A^{\alpha}$ implies that $D\left(A^{\alpha}\right)$, endowed with the graph norm of $A^{\alpha},|x|=\|x\|+\left\|A^{\alpha} x\right\|$, is a Banach space. Since $A^{\alpha}$ is invertible, its graph norm $|$.$| is equivalent to the norm |x|_{\alpha}=\left\|A^{\alpha} x\right\|$. Thus, $D\left(A^{\alpha}\right)$ equipped with the norm $|\cdot|_{\alpha}$, is a Banach space, which we denote by $X_{\alpha}$. The space $C_{\alpha}:=C\left([-r, 0], X_{\alpha}\right), r>0$ denotes the space of continuous functions from $[-r, 0]$ into $X_{\alpha}$ endowed with the uniform norm topology:

$$
\|\varphi\|_{\alpha}:=\sup _{\theta \in[-r, o]}|\varphi(\theta)|_{\alpha} \quad \text { for } \varphi \in C_{\alpha} .
$$

Also, the following properties are well known.

Theorem 2.1. 24] Let $0<\alpha<1$. Assume that the operator $-\mathrm{A}$ is the infinitesimal generator of an analytic semigroup $(T(t))_{t \geq 0}$ on the Banach space $X$ satisfying $0 \in \rho(A)$. Then we have

i) $\mathrm{T}(\mathrm{t}): \mathrm{X} \longrightarrow \mathrm{D}\left(\mathrm{A}^{\alpha}\right)$ for every $\mathrm{t}>0$,

ii) $T(t) A^{\alpha} x=A^{\alpha} T(t) x$ for every $x \in D\left(A^{\alpha}\right)$ and $t \geq 0$,

iii) for every $\mathrm{t}>0, \mathrm{~A}^{\alpha} \mathrm{T}(\mathrm{t})$ is bounded on $\mathrm{X}$ and there exist $\mathrm{M}_{\alpha}>0$ and $\delta>0$ such that

$$
\left\|A^{\alpha} T(t)\right\| \leq M_{\alpha} e^{-\delta t} t^{-\alpha} \leq M_{\alpha} t^{-\alpha} \quad \text { for } t>0,
$$


iv) If $0<\alpha \leq \beta<1$, then $\mathrm{D}\left(\mathrm{A}^{\beta}\right) \hookrightarrow \mathrm{D}\left(\mathrm{A}^{\alpha}\right)$.

v) There exists $\mathrm{N}_{\alpha}>0$ such that

$$
\left\|(\mathrm{T}(\mathrm{t})-\mathrm{I}) \mathrm{A}^{-\alpha}\right\| \leq \mathrm{N}_{\alpha} \mathrm{t}^{\alpha} \quad \text { for } \mathrm{t}>0 .
$$

vi) If $\mathrm{T}(\mathrm{t})$ is compact for each $\mathrm{t}>0$, then $\mathrm{A}^{-\alpha}$ is compact.

Now, we propose to find the existence of a mild solution for problem (2) using the sadovskii's fixed point theorem. Then, we obtain the uniqueness result of the solution by adding a hypothesis of Lipschitz continuous on F.

Let $E$ be a Banach space. We introduce the Kuratowskii measure of noncompactness $\chi(\Omega)$ of a set $\Omega \subset \mathrm{E}$ by

$$
\chi(\Omega)=\inf \{\varepsilon>0: \Omega \text { has a finite cover of diameter }<\varepsilon\} .
$$

Lemma 2.1. [10] Let $\mathrm{E}$ be a Banach Space and $\mathrm{B}, \mathrm{C} \subseteq \mathrm{E}$ be bounded set. Then, the following properties are true:

(1) $\mathrm{B}$ is relatively compact if and only if $\chi(\mathrm{B})=0$,

(2) $\chi(B+C) \leq \chi(B)+\chi(C)$, where $B+C=\{x+y: x \in B, y \in C\}$,

(3) Every Lipschitz continuous function K from C to F satisfies:

$$
\chi[K(\Omega)] \leq \operatorname{lipK} \chi(\Omega),
$$

where lip $K$ decides the smallest Lipschitz constant of $\mathrm{K}$.

Definition 2.2. [25] A mapping $\mathrm{K}$ from a set $\mathrm{C}$ in a Banach space $\mathrm{E}$ is called a condensing operator if it is continuous and for every bounded noncompact set $\Omega \subseteq \mathrm{C}$ the inequality holds

$$
\chi[K(\Omega)]<\chi(\Omega) .
$$

Theorem 2.2. [25](Sadovskii's fixed point theorem). If a condensing mapping $\mathrm{K}$ maps a bounded convex closed set $\mathrm{C}$ in a Banach space $\mathrm{E}$ into itself, then $\mathrm{K}$ has at least one fixed point in $\mathrm{T}$.

First of all, we study the existence of mild solutions, in order to do that, we assume the following assumptions.

(H0) The operator $-A$ is the infinitesimal generator of an analytic semigroup $(T(t))_{t \geq 0}$ on the Banach space $X$, moreover, we assume that $0 \in \rho(A)$.

(H1) The semigroup $(T(t))_{t \geq 0}$ is compact on $X$ for $t>0$. It means that $T(t)$ is compact on $X$ for $t>0$. 
(H2) $\mathrm{G}:[0, \mathrm{a}] \times \mathrm{C}_{\alpha} \rightarrow \mathrm{X}_{\alpha}$ is continuous and for each $\mathrm{a}>0$ there exists $0<\mathrm{L}_{\mathrm{g}}<1$ such that $|\mathrm{G}(\mathrm{t}, \varphi)-\mathrm{G}(\mathrm{t}, \psi)|_{\alpha} \leq \mathrm{L}_{\mathrm{g}}\|\varphi-\psi\|_{\alpha}$ for every $\mathrm{t} \in[0, \mathrm{a}]$ and $\varphi, \psi \in \mathrm{C}_{\alpha}$.

(H3) The function $\mathrm{F}:[0, \mathrm{a}] \times \mathrm{C}_{\alpha} \rightarrow \mathrm{X}$ satisfies the following conditions

i) $\mathrm{F}:[0, \mathrm{a}] \times \mathrm{C}_{\alpha} \rightarrow \mathrm{X}$ is continuous.

ii) There exists a continuous nondecreasing function $\beta:[0, a] \rightarrow \mathbb{R}_{+}$such that $\|\mathrm{F}(\mathrm{t}, \varphi)\| \leq$ $\beta(t)\|\varphi\|_{\alpha}$ for $(t, \varphi) \in[0, a] \times C_{\alpha}$.

Definition 2.3. A continuous function $\mathrm{x}:[-\mathrm{r}, \mathrm{a}] \longrightarrow \mathrm{X}_{\alpha}$, for $\mathrm{a}>0$ is said to be a mild solution of Eq. (2), if
i) $x(t)=T(t)[\varphi(0)-G(0, \varphi)]+G\left(t, x_{t}\right)+\int_{0}^{t} T(t-s) F\left(s, x_{s}\right) d s$ for $t \in[0, a]$,
ii) $x_{0}=\varphi$.

Definition 2.4. A continuous function $\mathrm{x}:[-\mathrm{r}, \mathrm{a}] \longrightarrow \mathrm{X}_{\alpha}$ is said to be a strict solution of Eq. (2), if

i) $x()-.G\left(., x_{(.)}\right) \in C^{1}\left([0, a], X_{\alpha}\right)$,

ii) $\frac{\mathrm{d}}{\mathrm{dt}}\left(\mathrm{x}(\mathrm{t})-\mathrm{G}\left(\mathrm{t}, \mathrm{x}_{\mathrm{t}}\right)\right)=-\mathrm{A}\left(\mathrm{x}(\mathrm{t})-\mathrm{G}\left(\mathrm{t}, \mathrm{x}_{\mathrm{t}}\right)\right)+\mathrm{F}\left(\mathrm{t}, \mathrm{x}_{\mathrm{t}}\right)$ for $\mathrm{t} \in[0, \mathrm{a}]$,

iii) $x_{0}=\varphi$.

Now, we state our first result.

Theorem 2.3. Assume that the hypothesis (HO)-(H3) hold. Let $\varphi \in \mathcal{C}_{\alpha}$. Assume that the following condition holds

$$
L_{g}+M_{\alpha} \int_{0}^{a} \frac{\beta(s)}{(a-s)^{\alpha}} d s<1 .
$$

Then Eq. (2) has at least one mild solution on $[0, \mathrm{a}]$.

Proof. Let $k>\|\varphi\|_{\alpha}$. We define the following set

$$
\mathrm{B}_{\mathrm{k}}=\left\{x \in \mathrm{C}\left([0, \mathrm{a}], \mathrm{X}_{\alpha}\right): x(0)=\varphi(0) \text { and }|x|_{\infty} \leq \mathrm{k}\right\}
$$

where $|x|_{\infty}=\sup _{t \in[0, a]}|x(t)|_{\alpha}$. For $x \in B_{k}$, define the mapping $\tilde{x}:[-r, a] \rightarrow X_{\alpha}$ by

$$
\tilde{x}(t)= \begin{cases}x(t) & \text { for } t \in[0, a] \\ \varphi(t) & \text { for } t \in[-r, 0] .\end{cases}
$$


The function $t \mapsto \tilde{x}_{t}$ is continuous from $[0, a]$ to $C_{\alpha}$.

Now, define the operator $\mathrm{K}$ on $\mathrm{B}_{\mathrm{k}}$ by

$$
K(x)(t)=T(t)(\varphi(0)-G(0, \varphi))+G\left(t, \tilde{x}_{t}\right)+\int_{0}^{t} T(t-s) F\left(s, \tilde{x}_{s}\right) d s \text { for } t \in[0, a] .
$$

It is sufficient to show that $K$ has a fixed point in $B_{k}$. We first show that there is a positive number $\mathrm{k}>\|\varphi\|_{\alpha}$ such that $\mathrm{K}\left(\mathrm{B}_{\mathrm{k}}\right) \subseteq \mathrm{B}_{\mathrm{k}}$. If not, then for each $\mathrm{k}>\|\varphi\|_{\alpha}$, there exist $x_{k} \in \mathrm{B}_{\mathrm{k}}$ and $t_{k} \in[0, a]$ such that $\left|\left(K x_{k}\right)\left(t_{k}\right)\right|_{\alpha}>k$. It follows that

$$
\begin{aligned}
k & <\left|\left(K x_{k}\right)\left(t_{k}\right)\right|_{\alpha} \\
& \leq\left|T\left(t_{k}\right)(\varphi(0)-G(0, \varphi))\right|_{\alpha}+\left|G\left(t_{k}, \tilde{x}_{t_{k}}\right)\right|_{\alpha}+\int_{0}^{t_{k}}\left|T\left(t_{k}-s\right) F\left(s, \tilde{x}_{s}\right)\right|_{\alpha} d s .
\end{aligned}
$$

Let $M=\sup \{\|T(t)\|: \quad t \in[0, a]\}$. Then

$$
\begin{aligned}
k< & M|\varphi(0)-G(0, \varphi)|_{\alpha}+\left|G\left(t_{k}, \tilde{x}_{t_{k}}\right)-G\left(t_{k}, 0\right)\right|_{\alpha}+\left|G\left(t_{k}, 0\right)\right|_{\alpha} \\
& +\int_{0}^{t_{k}} \frac{M_{\alpha}}{\left(t_{k}-s\right)^{\alpha}} \beta(s)\left\|\tilde{x}_{s}\right\|_{\alpha} d s .
\end{aligned}
$$

Moreover $\left\|\tilde{x}_{s}\right\|_{\alpha} \leq k$ for all $s \in[0, a]$ and $x \in B_{k}$. Then, we obtain

$$
k<M|\varphi(0)-G(0, \varphi)|_{\alpha}+\left|G\left(t_{k}, \tilde{x}_{t_{k}}\right)-G\left(t_{k}, 0\right)\right|_{\alpha}+\left|G\left(t_{k}, 0\right)\right|_{\alpha}+\int_{0}^{t_{k}} \frac{k M_{\alpha}}{\left(t_{k}-s\right)^{\alpha}} \beta(s) d s
$$

We shall show that the function $g: t \mapsto \int_{0}^{t} \frac{\beta(s)}{(t-s)^{\alpha}} d s$ is nondecreasing on $[0, a]$. Let $t, t^{\prime} \in[0, a]$ be such that $t<t^{\prime}$. Then we have

$$
g(t)=\int_{0}^{t} \frac{\beta(t-s)}{s^{\alpha}} d s \leq \int_{0}^{t} \frac{\beta\left(t^{\prime}-s\right)}{s^{\alpha}} d s \leq \int_{0}^{t^{\prime}} \frac{\beta\left(t^{\prime}-s\right)}{s^{\alpha}} d s=g\left(t^{\prime}\right) .
$$

Therefore

$$
k \leq M|\varphi(0)-G(0, \varphi)|_{\alpha}+L_{g}\left\|\tilde{x}_{t_{k}}\right\|_{\alpha}+\sup _{0 \leq s \leq a}|G(s, 0)|_{\alpha}+\int_{0}^{a} \frac{k M_{\alpha}}{(a-s)^{\alpha}} \beta(s) d s .
$$

Dividing both sides by $k$ and taking the lower limit as $k \rightarrow+\infty$, then we get that

$$
\mathrm{L}_{g}+\mathrm{M}_{\alpha} \int_{0}^{\mathrm{a}} \frac{\beta(\mathrm{s})}{(\mathrm{a}-\mathrm{s})^{\alpha}} \mathrm{ds} \geq 1
$$

which contradicts (5). Consequently, there exists $\mathrm{k} \geq 0$ such $\mathrm{K}\left(\mathrm{B}_{\mathrm{k}}\right) \subseteq \mathrm{B}_{\mathrm{k}}$.

To prove that $K$ has at least a fixed point on $B_{k}$, we decompose $K$ as follows $K:=K_{1}+K_{2}$, where

$$
K_{1}(x)(t)=G\left(t, \tilde{x}_{t}\right) \quad \text { for } t \in[0, a] .
$$

and

$$
\mathrm{K}_{2}(x)(\mathrm{t})=\mathrm{T}(\mathrm{t})(\varphi(0)-\mathrm{G}(0, \varphi))+\int_{0}^{\mathrm{t}} \mathrm{T}(\mathrm{t}-\mathrm{s}) \mathrm{F}\left(\mathrm{s}, \tilde{\mathrm{x}}_{\mathrm{s}}\right) \mathrm{ds} \quad \text { for } \mathrm{t} \in[0, \mathrm{a}]
$$


We claim that $K_{1}$ is a strict contraction and $K_{2}$ is compact.

To see this, observe that for $t \in[0, a]$ and $x, y \in B_{k}$, we have by assumption (H2).

$$
\begin{aligned}
\left|K_{1} x(t)-K_{1} y(t)\right|_{\alpha} & =\left|G\left(t, \tilde{x}_{t}\right)-G\left(t, \tilde{y}_{t}\right)\right|_{\alpha} \\
& \leq L_{g}\left\|\tilde{x}_{t}-\tilde{y}_{t}\right\|_{\alpha} \\
& \leq L_{g}|x-y|_{\infty}
\end{aligned}
$$

Then $\mathrm{K}_{1}$ is a strict contraction. We will prove now the continuity of $\mathrm{K}_{2}$. Let $\left(x^{n}\right)_{n} \subset \mathrm{B}_{\mathrm{k}}$ with $x^{n} \rightarrow x$ in $B_{k}$. Then, the set $\Lambda=\left\{\left(s, \tilde{x}_{s}^{n}\right),\left(s, \tilde{x}_{s}\right): s \in[0, a], n \geq 1\right\}$ is compact in $[0, a] \times C_{\alpha}$. By Heïne's theorem implies that $F$ is uniformly continuous in $\Lambda$ and

$$
\begin{aligned}
\left|K_{2}\left(x^{n}\right)-K_{2}(x)\right|_{\infty} & =\sup _{t \in[0, a]} \int_{0}^{t} A^{\alpha} T(t-s)\left(F\left(s, \tilde{x}_{s}^{n}\right)-F\left(s, \tilde{x}_{s}\right)\right) d s \\
& \leq M_{\alpha} \int_{0}^{a} \frac{d s}{s^{\alpha}} \sup _{s \in[0, a]}\left\|F\left(s, \tilde{x}_{s}^{n}\right)-F\left(s, \tilde{x}_{s}\right)\right\| \rightarrow 0 \text { as } n \rightarrow+\infty
\end{aligned}
$$

and this yield the continuity of $\mathrm{K}_{2}$, then the continuity of $\mathrm{K}$ on $\mathrm{B}_{\mathrm{k}}$.

We next show that the operator $\mathrm{K}_{2}$ is compact.

In order to apply Ascoli theorem we have to show that the set $\left\{K_{2}(x)(t): x \in B_{k}\right\}$ is relatively compact for each $t \in] 0, a]$.

Let $t \in] 0$, a] be fixed, and $\gamma>0$ be such that $\alpha<\gamma<1$. Then

$$
\begin{aligned}
\left\|\left(A^{\gamma} K_{2}(x)\right)(t)\right\| & \leq\left\|A^{\gamma} \mathrm{T}(\mathrm{t})(\varphi(0)-\mathrm{G}(0, \varphi))\right\|+\left\|\int_{0}^{t} A^{\gamma} \mathrm{T}(\mathrm{t}-\mathrm{s}) \mathrm{F}\left(s, \tilde{x}_{s}\right) \mathrm{d} s\right\| \\
& \leq M_{\gamma} \mathrm{t}^{-\gamma}\|\varphi(0)-\mathrm{G}(0, \varphi)\|+k M_{\gamma} \int_{0}^{t}(\mathrm{t}-s)^{-\gamma} \beta(s) \mathrm{d} s<+\infty .
\end{aligned}
$$

Then for fixed $t \in] 0, a],\left\{\left(A^{\gamma} K_{2} x\right)(t)\right\}$ is bounded in X. Appealing (H1) and (vi) of Theorem 2.1, we deduce that $A^{-\gamma}: X \rightarrow X_{\alpha}$ is compact, it follows that $\left\{K_{2}(x)(t): x \in B_{k}\right\}$ is relatively compact set in $X_{\alpha}$.

Next, we will show that $\left\{K_{2} x: x \in B_{k}\right\}$ is an equicontinuous family of functions. For $0 \leq t_{1}<$ $\mathrm{t}_{2} \leq \mathrm{a}$

$$
\begin{aligned}
K_{2} x\left(t_{2}\right)-K_{2} x\left(t_{1}\right)= & \left(T\left(t_{2}\right)-T\left(t_{1}\right)\right)(\varphi(0)-G(0, \varphi))+\int_{t_{1}}^{t_{2}} T\left(t_{2}-s\right) F\left(s, \widetilde{x}_{s}\right) d s \\
& +\int_{0}^{t_{1}}\left(T\left(t_{2}-s\right)-T\left(t_{1}-s\right)\right) F\left(s, \widetilde{x}_{s}\right) d s \\
= & \left(T\left(t_{2}\right)-T\left(t_{1}\right)\right)(\varphi(0)-G(0, \varphi))+\int_{t_{1}}^{t_{2}} T\left(t_{2}-s\right) F\left(s, \widetilde{x}_{s}\right) d s \\
& +\left(T\left(t_{2}-t_{1}\right)-I\right) \int_{0}^{t_{1}} T\left(t_{1}-s\right) F\left(s, \widetilde{x}_{s}\right) d s .
\end{aligned}
$$


We obtain that

$$
\begin{aligned}
\left|K_{2} x\left(t_{2}\right)-K_{2} x\left(t_{1}\right)\right|_{\alpha} \leq & \left\|\left(T\left(t_{2}\right)-T\left(t_{1}\right)\right) A^{\alpha}(\varphi(0)-G(0, \varphi))\right\|+k M_{\alpha}\|\beta\|_{\infty} \int_{t_{1}}^{t_{2}}\left(t_{2}-s\right)^{-\alpha} d s \\
& +\left\|\left(T\left(t_{2}-t_{1}\right)-I\right) \int_{0}^{t_{1}} A^{\alpha} T\left(t_{1}-s\right) F\left(s, \widetilde{x}_{s}\right) d s\right\|
\end{aligned}
$$

It's clair to prove the first part tend to zero as $\left|t_{2}-t_{1}\right| \rightarrow 0$. Since for $t_{1}>0$ the set

$$
\left\{\int_{0}^{t_{1}} A^{\alpha} T\left(t_{1}-s\right) F\left(s, \widetilde{x}_{s}\right) d s: x \in B_{k}\right\}
$$

is relatively compact in $X$, there is a compact set $\widetilde{K}$ in $X$ such that

$$
\int_{0}^{t_{1}} A^{\alpha} T\left(t_{1}-s\right) F\left(s, \widetilde{x}_{s}\right) d s \in \widetilde{K} \text { for } x \in B_{k} .
$$

By Banach-Steinhaus's theorem, we have

$$
\left\|\left(T\left(t_{2}-t_{1}\right)-I\right) \int_{0}^{t_{1}} A^{\alpha} T\left(t_{1}-s\right) F\left(s, \widetilde{x}_{s}\right) d s\right\| \rightarrow 0 \text { as } t_{2} \rightarrow t_{1},
$$

uniformly in $x \in B_{k}$. Using similar argument for $0 \leq t_{2}<t_{1} \leq a$, we can conclude that $\left\{K_{2} x(t), x \in B_{k}\right\}$ is an equicontinuous . Using Ascoli-Arzla theorem, we deduce that $K_{2}: B_{k} \rightarrow B_{k}$ is compact, and $K=K_{1}+K_{2}$ is a condensing operator. By the Sadovskii's fixed-point theorem 2.2. we conclude that $K$ has at least one fixed point in $B_{k}$, which is a mild solutions of Eq. (2) on $[0, a]$.

To prove result on uniqueness, we to assume that

(H4) $\mathrm{F}:[0, \mathrm{a}] \times \mathrm{C}_{\alpha} \rightarrow \mathrm{X}$ is continuous and Lipschitzian with respect to the second variable. Let $\mathrm{L}_{\mathrm{f}}>0$ be such that

$$
\left\|\mathrm{F}\left(\mathrm{t}, \psi_{1}\right)-\mathrm{F}\left(\mathrm{t}, \psi_{2}\right)\right\| \leqslant \mathrm{L}_{\mathrm{f}}\left\|\psi_{1}-\psi_{2}\right\|_{\alpha}
$$

for every $\psi_{1}, \psi_{2} \in C_{\alpha}$ and $t \in[0, a]$.

Theorem 2.4. Let $\varphi \in \mathrm{C}_{\alpha}$. If the assumptions (HO), (H2) and (H4) are satisfied, then Eq. (2) has a unique mild solution provided that

$$
\mathrm{L}_{\mathrm{g}}+\mathrm{M}_{\alpha} \mathrm{L}_{\mathrm{f}} \frac{\mathrm{a}^{1-\alpha}}{1-\alpha}<1 .
$$

Proof. Consider the nonempty closed subset of $\mathrm{C}\left([0, \mathrm{a}], \mathrm{X}_{\alpha}\right)$ defined by

$$
\Omega(\varphi):=\left\{x \in \mathrm{C}\left([0, \mathrm{a}], \mathrm{X}_{\alpha}\right): \chi(0)=\varphi(0)\right\} .
$$

For $x \in \Omega(\varphi)$, define the mapping $\tilde{x}:[-r, a] \rightarrow X_{\alpha}$ by

$$
\tilde{x}(t)= \begin{cases}x(t) & \text { for } t \in[0, a] \\ \varphi(t) & \text { for } t \in[-r, 0] .\end{cases}
$$


Define the operator $\mathrm{K}: \Omega(\varphi) \rightarrow \Omega(\varphi)$ by

$$
\mathrm{K}(\mathrm{x})(\mathrm{t})=\mathrm{T}(\mathrm{t})(\varphi(0)-\mathrm{G}(0, \varphi))+\mathrm{G}\left(\mathrm{t}, \tilde{x}_{\mathrm{t}}\right)+\int_{0}^{\mathrm{t}} \mathrm{T}(\mathrm{t}-\mathrm{s}) \mathrm{F}\left(\mathrm{s}, \tilde{x}_{\mathrm{s}}\right) \mathrm{ds} \text { for } \mathrm{t} \in[0, \mathrm{a}] .
$$

We shall show that it is a strict contraction. Let $x, y \in \Omega(\varphi)$ and $t \in[0, a]$. Then

$$
\begin{aligned}
|K x(t)-K y(t)|_{\alpha} & \leqslant\left|G\left(t, \tilde{x}_{t}\right)-G\left(t, \tilde{y}_{t}\right)\right|_{\alpha}+\int_{0}^{t}\left|T(t-s)\left\{F\left(s, \tilde{x}_{s}\right)-F\left(s, \tilde{y}_{s}\right)\right\}\right|_{\alpha} d s \\
& \leqslant L_{g}\left\|\tilde{x}_{t}-\tilde{y}_{t}\right\|_{\alpha}+M_{\alpha} \int_{0}^{t}\left\|F\left(s, \tilde{x}_{s}\right)-F\left(s, \tilde{y}_{s}\right)\right\|(t-s)^{-\alpha} d s \\
& \leqslant\left(L_{g}+M_{\alpha} L_{f} \frac{a^{1-\alpha}}{1-\alpha}\right)|x-y|_{\infty}
\end{aligned}
$$

Then

$$
|K x-K y|_{\infty} \leqslant\left(L_{g}+M_{\alpha} L_{f} \frac{a^{1-\alpha}}{1-\alpha}\right)|x-y|_{\infty}
$$

It follows that $K$ is a strict contraction since $L_{g}+M_{\alpha} L_{f} \frac{a^{1-\alpha}}{1-\alpha}<1$. By the contraction principle, we conclude that there exists a unique fixed point $x$ for $K$ in $\Omega(\varphi)$, therefore Eq. (2) has a unique mild solution on $[-r, a]$. The proof is completed.

\section{$3 \quad$ Existence of strict solutions}

For the regularity of the integral solutions, we suppose moreover the following assumptions:

(H5) $\mathrm{G}$ and $\mathrm{F}$ are continuously differentiable and their partial derivatives are locally Lipschitzian with respect to the second argument in the sense that; for any compact set $\mathrm{K} \subset[0, \mathrm{a}] \times \mathrm{C}_{\alpha}$, there exist positive constants $\mathrm{L}_{1}, \mathrm{E}_{2}, \mathrm{~L}_{3}$ and $\mathrm{L}_{4}$ such that

$$
\begin{aligned}
& \left|D_{1} G\left(t, \psi_{1}\right)-D_{1} G\left(t, \psi_{2}\right)\right|_{\alpha} \leqslant L_{1}\left\|\psi_{1}-\psi_{2}\right\|_{\alpha} \\
& \left\|D_{2} G\left(t, \psi_{1}\right)-D_{2} G\left(t, \psi_{2}\right)\right\|_{\mathcal{L}\left(C_{\alpha}, x_{\alpha}\right)} \leqslant L_{2}\left\|\psi_{1}-\psi_{2}\right\|_{\alpha} \\
& \left\|D_{1} F\left(t, \psi_{1}\right)-D_{1} F\left(t, \psi_{2}\right)\right\| \leqslant L_{3}\left\|\psi_{1}-\psi_{2}\right\|_{\alpha} \\
& \left\|D_{2} F\left(t, \psi_{1}\right)-D_{2} F\left(t, \psi_{2}\right)\right\|_{\mathcal{L}\left(C_{\alpha}, x\right)} \leqslant L_{4}\left\|\psi_{1}-\psi_{2}\right\|_{\alpha}
\end{aligned}
$$

for $\left(t, \psi_{1}\right),\left(t, \psi_{2}\right) \in K$ and $t \in[0, a]$. Where $D_{1}$ and $D_{2}$ are the partial derivatives with respect to the first and second argument.

Theorem 3.1. Assume that (HO),(H2), (H4), (H5) hold and condition (7) is true. Let $\varphi \in$ $\mathrm{C}^{1}\left([-\mathrm{r}, 0], \mathrm{X}_{\alpha}\right)$ be such that $\varphi(0)-\mathrm{G}(0, \varphi) \in \mathrm{D}(\mathrm{A})$ and

$$
\varphi^{\prime}(0)-\mathrm{D}_{1} \mathrm{G}(0, \varphi)-\mathrm{D}_{2} \mathrm{G}(0, \varphi) \varphi^{\prime}=-\mathrm{A}[\varphi(0)-\mathrm{G}(0, \varphi)]+\mathrm{F}(0, \varphi)
$$

Then Eq. (2) has a unique strict solution on $[0, \mathrm{a}]$. 
Proof. Let $x$ be the mild solution of Eq. (2). Consider the equation

$$
\left\{\begin{aligned}
y(t) & =T(t)[-A(\varphi(0)-G(0, \varphi))+F(0, \varphi)]+D_{1} G\left(t, x_{t}\right)+D_{2} G\left(t, x_{t}\right) y_{t} \\
& +\int_{0}^{t} T(t-s)\left[D_{1} F\left(s, x_{s}\right)+D_{2} F\left(s, x_{s}\right) y_{s}\right] d s \quad \text { for } t \in[0, a] \\
y_{0} & =\varphi^{\prime} \in C_{\alpha} .
\end{aligned}\right.
$$

We claim that Eq. (8) has a unique solution on $[0, a]$. In fact, consider the operator $\mathrm{P}$ defined on $\Lambda:=\left\{x \in C\left([-r, a] ; X_{\alpha}\right): x(t)=\varphi^{\prime}(t)\right.$ for $\left.t \in[-r, 0]\right\}$ by

$$
\operatorname{Py}(t)= \begin{cases}T(t)[-A(\varphi(0)-G(0, \varphi))+F(0, \varphi)]+D_{1} G\left(t, x_{t}\right) & \\ +D_{2} G\left(t, x_{t}\right) y_{t}+\int_{0}^{t} T(t-s)\left[D_{1} F\left(s, x_{s}\right)+D_{2} F\left(s, x_{s}\right) y_{s}\right] d s & \text { for } t \in[0, a], \\ \varphi^{\prime}(t) & \text { for } t \in[-r, 0] .\end{cases}
$$

Let $u, v \in \Lambda$. Then for each $t \in[0, a]$, we have

$$
\begin{aligned}
|\mathrm{Pu}(\mathrm{t})-\mathrm{P} v(\mathrm{t})|_{\alpha} \leqslant & \left\|\mathrm{D}_{2} \mathrm{G}\left(\mathrm{t}, \mathrm{x}_{\mathrm{t}}\right)\right\|_{\mathcal{L}\left(\mathrm{C}_{\alpha}, \mathrm{X}_{\alpha}\right)}\left\|\mathrm{u}_{\mathrm{t}}-v_{\mathrm{t}}\right\|_{\alpha} \\
& +\mathrm{M}_{\alpha} \int_{0}^{\mathrm{t}}\left\|\mathrm{D}_{2} \mathrm{~F}\left(\mathrm{~s}, \mathrm{x}_{s}\right)\right\|_{\mathcal{L}\left(\mathrm{C}_{\alpha}, \mathrm{X}\right)}\left\|\mathrm{u}_{\mathrm{s}}-v_{s}\right\|_{\alpha} \frac{\mathrm{d} s}{(\mathrm{t}-\mathrm{s})^{\alpha}} \\
\leqslant & \left(\mathrm{L}_{\mathrm{g}}+\mathrm{M}_{\alpha} \mathrm{L}_{\mathrm{f}} \frac{\mathrm{a}^{1-\alpha}}{1-\alpha}\right)|\mathrm{u}-v|_{\infty} .
\end{aligned}
$$

Then $\mathrm{P}$ is a strict contraction. Consequently, it has a unique mild solution $\mathrm{y}$.

Define $z:[-r, a] \rightarrow X_{\alpha}$ by

$$
z(t)= \begin{cases}\varphi(0)+\int_{0}^{t} y(s) d s & \text { for } t \in[0, a] \\ \varphi(t) & \text { for } t \in[-r, 0]\end{cases}
$$

we will show that $z(t)=x(t)$ on $[0, a]$.

For $\mathrm{t} \in[0, \mathrm{a}]$, we have

$$
\begin{aligned}
z(t)= & \varphi(0)+\int_{0}^{t} T(s)(-A)(\varphi(0)-G(0, \varphi)) d s+\int_{0}^{t} T(s) F(0, \varphi) d s \\
& +\int_{0}^{t} D_{1} G\left(s, x_{s}\right)+D_{2} G\left(s, x_{s}\right) y_{s} d s \\
& +\int_{0}^{t} \int_{0}^{s} T(s-\tau)\left[D_{1} F\left(\tau, x_{\tau}\right)+D_{2} F\left(\tau, x_{\tau}\right) y_{\tau}\right] d \tau d s .
\end{aligned}
$$

Moreover, we can see that

$$
z_{t}=\varphi+\int_{0}^{t} y_{s} d s \quad \text { for } t \in[0, a]
$$


Then $\mathrm{t} \mapsto z_{\mathrm{t}}$ and $\mathrm{t} \mapsto \int_{0}^{\mathrm{t}} \mathrm{T}(\mathrm{t}-\mathrm{s}) \mathrm{F}\left(\mathrm{s}, z_{\mathrm{s}}\right)$ ds are continuously differentiable on $[0, \mathrm{a}]$ and satisfy

$$
\frac{d}{d t} \int_{0}^{t} T(t-s) F\left(s, z_{s}\right) d s=T(t) F(0, \varphi)+\int_{0}^{t} T(t-s)\left[D_{1} F\left(s, z_{s}\right)+D_{2} F\left(s, z_{s}\right) y_{s}\right] d s,
$$

then (10) yields

$$
\begin{aligned}
\int_{0}^{t} T(s) F(0, \varphi) d s= & \int_{0}^{t} T(t-s) F\left(s, z_{s}\right) d s \\
& -\int_{0}^{t} \int_{0}^{s} T(s-\tau)\left[D_{1} F\left(\tau, z_{\tau}\right)+D_{2} F\left(\tau, z_{\tau}\right) y_{\tau}\right] d \tau d s .
\end{aligned}
$$

On the other hand

$$
\begin{aligned}
\mathrm{G}\left(\mathrm{t}, z_{\mathrm{t}}\right) & =\mathrm{G}(0, \varphi)+\int_{0}^{\mathrm{t}} \frac{\mathrm{d}}{\mathrm{ds}} \mathrm{G}\left(\mathrm{s}, z_{\mathrm{s}}\right) \mathrm{ds} \\
& =\mathrm{G}(0, \varphi)+\int_{0}^{\mathrm{t}} \mathrm{D}_{1} \mathrm{G}\left(\mathrm{s}, z_{\mathrm{s}}\right)+\mathrm{D}_{2} \mathrm{G}\left(\mathrm{s}, z_{\mathrm{s}}\right) \mathrm{y}_{\mathrm{s}} \mathrm{ds}
\end{aligned}
$$

Then

$$
\begin{aligned}
z(t)= & T(t)(\varphi(0)-G(0, \varphi))+G\left(t, z_{t}\right)-\int_{0}^{t} D_{1} G\left(s, z_{s}\right)+D_{2} G\left(s, z_{s}\right) y_{s} d s \\
& +\int_{0}^{t} T(t-s) F\left(s, z_{s}\right) d s-\int_{0}^{t} \int_{0}^{s} T(s-\tau)\left[D_{1} F\left(\tau, z_{\tau}\right)+D_{2} F\left(\tau, z_{\tau}\right) y_{\tau}\right] d \tau d s \\
& +\int_{0}^{t}\left(D_{1} G\left(s, x_{s}\right)+D_{2} G\left(s, x_{s}\right) y_{s}\right) d s+\int_{0}^{t} \int_{0}^{s} T(s-\tau)\left[D_{1} F\left(\tau, x_{\tau}\right)+D_{2} F\left(\tau, x_{\tau}\right) y_{\tau}\right] d \tau d s
\end{aligned}
$$

Therefore

$$
\begin{aligned}
|z(t)-x(t)|_{\alpha} \leq & \left|G\left(t, z_{t}\right)-G\left(t, x_{t}\right)\right|_{\alpha}+\int_{0}^{t}\left|D_{1} G\left(s, z_{s}\right)-D_{1} G\left(s, x_{s}\right)\right|_{\alpha} d s \\
& +\int_{0}^{t}\left|D_{2} G\left(s, z_{s}\right) y_{s}-D_{2} G\left(s, x_{s}\right) y_{s}\right|_{\alpha} d s \\
& +\int_{0}^{t}\left|T(t-s)\left(F\left(s, z_{s}\right)-F\left(s, x_{s}\right)\right)\right|_{\alpha} d s \\
& +\int_{0}^{t} \int_{0}^{s}\left|T(s-\tau)\left[D_{1} F\left(\tau, z_{\tau}\right)-D_{1} F\left(\tau, x_{\tau}\right)\right]\right|_{\alpha} d \tau d s \\
& +\int_{0}^{t} \int_{0}^{s}\left|T(s-\tau)\left[D_{2} F\left(\tau, z_{\tau}\right) y_{\tau}-D_{2} F\left(\tau, x_{\tau}\right) y_{\tau}\right]\right|_{\alpha} d \tau d s
\end{aligned}
$$

Note that the sets $\left\{\left(s, z_{s}\right): s \in[0, a]\right\}$ and $\left\{\left(s, x_{s}\right): s \in[0, a]\right\}$ are compacts in $[0, a] \times C_{\alpha}$, since the mapping $t \rightarrow z_{t}$ and $t \rightarrow x_{t}$ are continuous on $[0, a]$. Then, we deduce that

$$
\begin{aligned}
& \left\|D_{1} G\left(s, z_{s}\right)-D_{1} G\left(s, x_{s}\right)\right\|_{\alpha} \leqslant L_{1}\left\|z_{s}-x_{s}\right\|_{\alpha}, \\
& \left\|\mathrm{D}_{2} \mathrm{G}\left(\mathrm{s}, z_{\mathrm{s}}\right)-\mathrm{D}_{2} \mathrm{G}\left(\mathrm{s}, \mathrm{x}_{\mathrm{s}}\right)\right\|_{\mathcal{L}\left(\mathrm{C}_{\alpha}, \mathrm{x}_{\alpha}\right)} \leqslant \mathrm{L}_{2}\left\|z_{\mathrm{s}}-x_{\mathrm{s}}\right\|_{\alpha} \text {, } \\
& \left\|\mathrm{D}_{1} \mathrm{~F}\left(\mathrm{~s}, z_{\mathrm{s}}\right)-\mathrm{D}_{1} \mathrm{~F}\left(\mathrm{~s}, \mathrm{x}_{\mathrm{s}}\right)\right\| \leqslant \mathrm{L}_{3}\left\|z_{\mathrm{s}}-x_{\mathrm{s}}\right\|_{\alpha}, \\
& \left\|D_{2} \mathrm{~F}\left(s, z_{s}\right)-D_{2} \mathrm{~F}\left(s, x_{s}\right)\right\|_{\mathcal{L}\left(C_{\alpha}, X\right)} \leqslant L_{4}\left\|z_{s}-x_{s}\right\|_{\alpha} \text {, }
\end{aligned}
$$


for all $s \in[0, a], x \in \Lambda$ and $z$ given in (9). Let $L=\max \left\{L_{f}, L_{1}, L_{2}, L_{3}, L_{4}\right\}$. Then

$$
\begin{aligned}
|z(t)-x(t)|_{\alpha} \leq & L_{g}+L\left(t+\|y\|_{\infty} t+\frac{M_{\alpha}}{1-\alpha} t^{1-\alpha}+\frac{M_{\alpha}}{(1-\alpha)(2-\alpha)} t^{2-\alpha}\right. \\
& \left.+\frac{M_{\alpha}\|y\|_{\infty}}{(1-\alpha)(2-\alpha)} \mathrm{t}^{2-\alpha}\right) \sup _{0 \leq s \leq t}|z(s)-x(s)|_{\alpha} .
\end{aligned}
$$

We can choose $t_{0} \in[0, a]$ such that

$$
\mathrm{L}_{g}+\mathrm{L}\left(\mathrm{t}_{0}+\|y\|_{\infty} \mathrm{t}_{0}+\frac{M_{\alpha}}{1-\alpha} \mathrm{t}_{0}^{1-\alpha}+\frac{M_{\alpha}}{(1-\alpha)(2-\alpha)} \mathrm{t}_{0}^{2-\alpha}+\frac{M_{\alpha}\|y\|_{\infty}}{(1-\alpha)(2-\alpha)} \mathrm{t}_{0}^{2-\alpha}\right)<1 .
$$

we deduce that $x=z$ on $\left[0, t_{0}\right]$. We claim that $x(t)=z(t)$ for $t \in[0, a]$. We proceed by contradiction and assume that there exists $t_{1} \in[0, a]$ such that $x\left(t_{1}\right) \neq z\left(t_{1}\right)$. Let $t^{*}$ be the smallest number such that $x(t) \neq z(t)$. Then

$$
t^{*}=\inf \left\{t \in[0, a]:|z(t)-x(t)|_{\alpha}>0\right\} .
$$

By continuity, one has $x(t)=z(t)$ for $t \in\left[0, t^{*}\right]$ and there exists $\varepsilon>0$ such that

$$
\left.|z(t)-x(t)|_{\alpha}>0 \text { for } t \in\right] t^{*}, t^{*}+\varepsilon[.
$$

It follows for $t \in\left[t^{*}, t^{*}+\varepsilon\right]$ that

$$
\begin{aligned}
|z(t)-x(t)|_{\alpha} \leq & \left|G\left(t, z_{t}\right)-G\left(t, x_{t}\right)\right|_{\alpha}+\int_{t^{*}}^{t}\left|D_{1} G\left(s, z_{s}\right)-D_{1} G\left(s, x_{s}\right)\right|_{\alpha} d s \\
& +\int_{t^{*}}^{t}\left|D_{2} G\left(s, z_{s}\right) y_{s}-D_{2} G\left(s, x_{s}\right) y_{s}\right|_{\alpha} d s \\
& +\int_{t^{*}}^{t}\left|T(t-s)\left(F\left(s, z_{s}\right)-F\left(s, x_{s}\right)\right)\right|_{\alpha} d s \\
& +\int_{t^{*}}^{t} \int_{t^{*}}^{s}\left|T(s-\tau)\left[D_{1} F\left(\tau, z_{\tau}\right)-D_{1} F\left(\tau, x_{\tau}\right)\right]\right|_{\alpha} d \tau d s \\
& +\int_{t^{*}}^{t} \int_{t^{*}}^{s}\left|T(s-\tau)\left[D_{2} F\left(\tau, z_{\tau}\right) y_{\tau}-D_{2} F\left(\tau, x_{\tau}\right) y_{\tau}\right]\right|_{\alpha} d \tau d s .
\end{aligned}
$$

Consequently,

$$
\begin{aligned}
|z(\mathrm{t})-x(\mathrm{t})|_{\alpha} \leq & \mathrm{L}_{g}+\mathrm{L}\left(\varepsilon+\|y\|_{\infty} \varepsilon+\frac{\mathrm{M}_{\alpha}}{1-\alpha} \varepsilon^{1-\alpha}+\frac{\mathrm{M}_{\alpha}}{(1-\alpha)(2-\alpha)} \varepsilon^{2-\alpha}\right. \\
& \left.+\frac{\mathrm{M}_{\alpha}\|y\|_{\infty}}{(1-\alpha)(2-\alpha)} \varepsilon^{2-\alpha}\right)_{\mathrm{t}^{*} \leq s \leq \mathrm{t}^{*}+\varepsilon}|z(s)-x(s)|_{\alpha} .
\end{aligned}
$$

If we choose $\varepsilon$ such that

$$
\mathrm{L}_{g}+\mathrm{L}\left(\varepsilon+\|y\|_{\infty} \varepsilon+\frac{M_{\alpha}}{1-\alpha} \varepsilon^{1-\alpha}+\frac{M_{\alpha}}{(1-\alpha)(2-\alpha)} \varepsilon^{2-\alpha}+\frac{M_{\alpha}\|y\|_{\infty}}{(1-\alpha)(2-\alpha)} \varepsilon^{2-\alpha}\right)<1
$$

then $x(t)=z(t)$ for $t \in\left[t^{*}, t^{*}+\varepsilon\right]$ which gives a contradiction. Consequently $x(t)=z(t)$ for $t \in[0, a]$ and $t \mapsto x_{t}$ is continuously differentiable in $[0, a]$ and $t \mapsto F\left(t, x_{t}\right) \in C^{1}([0, a], X)$. To end the proof, we use the following lemma. 
Lemma 3.1. 24] Let $\mathrm{h}:[0, \mathrm{a}] \rightarrow \mathrm{X}$ be continuously differentiable and $\mathrm{u}$ satisfy

$$
\mathrm{u}(\mathrm{t})=\mathrm{T}(\mathrm{t}) \mathrm{u}_{0}+\int_{0}^{\mathrm{t}} \mathrm{T}(\mathrm{t}-\mathrm{s}) \mathrm{h}(\mathrm{s}) \mathrm{ds} \quad \text { for } \mathrm{t} \in[0, \mathrm{a}]
$$

If $\mathrm{u}_{\mathrm{O}} \in \mathrm{D}(\mathrm{A})$, then $\mathrm{u}$ is continuously differentiable on $[0, \mathrm{a}]$ and

$$
u^{\prime}(t)=-A u(t)+h(t) \quad \text { for } t \in[0, a] .
$$

In our case, we have $\varphi(0)-\mathrm{G}(0, \varphi) \in \mathrm{D}(\mathrm{A}), \mathrm{t} \mapsto \mathrm{F}\left(\mathrm{t}, \mathrm{x}_{\mathrm{t}}\right)$ is continuously differentiable on $[0, a]$ and

$$
x(t)-G\left(t, x_{t}\right)=T(t)[\varphi(0)-G(0, \varphi)]+\int_{0}^{t} T(t-s) F\left(s, x_{s}\right) d s \text { for } t \in[0, a]
$$

By Lemma 3.1, the mapping $t \mapsto x(t)-G\left(t, x_{t}\right)$ is continuously differentiable on [0, a] and for $t \in[0, a]$,

$$
\frac{d}{d t}\left[x(t)-G\left(t, x_{t}\right)\right]=-A\left[x(t)-G\left(t, x_{t}\right)\right]+F\left(t, x_{t}\right) \text { for } t \in[0, a]
$$

These implies that $x$ is a strict solution of Eq. (2) on $[0, a]$.

\section{The solution semigroup in the autonomous case and the linearized stability principle}

In this section, we suppose that F and G are autonomous. Then Eq. (2) becomes

$$
\left\{\begin{array}{l}
\frac{d}{d t}\left[x(t)-G\left(x_{t}\right)\right]=-A\left[x(t)-G\left(x_{t}\right)\right]+F\left(x_{t}\right) \quad \text { for } t \geq 0 \\
x_{0}=\varphi \in C_{\alpha} .
\end{array}\right.
$$

We can see that the mild solutions of Eq. (11) satisfy the properties of a nonlinear strongly continuous semigroup on $C_{\alpha}$ and we prove that this semigroup satisfies the translation property and a Lipschitz property.

For each $t \geq 0$, define the nonlinear operator $\mathrm{U}(\mathrm{t})$ on $\mathrm{C}_{\alpha}$ by

$$
\mathrm{u}(\mathrm{t})(\varphi)=\chi_{\mathrm{t}}(., \varphi)
$$

where $x(., \varphi)$ is the unique mild solution of Eq. (11) for the initial condition $\varphi \in \mathrm{C}_{\alpha}$. One can prove the proposition.

Proposition 4.1. Under the assumption as in the Theorem 2.4), the family $(\mathrm{U}(\mathrm{t}))_{\mathrm{t} \geqslant 0}$ is a nonlinear strongly continuous semigroup on $\mathrm{C}_{\alpha}$. Moreover

(i) $(\mathrm{U}(\mathrm{t}))_{\mathrm{t} \geqslant 0}$ satisfies the following translation property, for $\mathrm{t} \geqslant 0$ and $\theta \in[-\mathrm{r}, 0]$,

$$
(\mathrm{U}(\mathrm{t})(\varphi))(\theta)= \begin{cases}(\mathrm{U}(\mathrm{t}+\theta)(\varphi))(0), & \text { if } \mathrm{t}+\theta \geqslant 0 \\ \varphi(\mathrm{t}+\theta), & \text { if } \mathrm{t}+\theta \leqslant 0\end{cases}
$$


(ii) for all $\mathrm{T}>0$, there are two functions $\mathrm{p}, \mathrm{q} \in \mathrm{L}^{\infty}\left([0, \mathrm{~T}], \mathbb{R}^{+}\right)$such that, for all $\varphi_{1}, \varphi_{2} \in \mathrm{C}_{\alpha}$,

$$
\left\|\mathrm{U}(\mathrm{t})\left(\varphi_{1}\right)-\mathrm{U}(\mathrm{t})\left(\varphi_{2}\right)\right\|_{\alpha} \leq p(t) e^{q(t)}\left\|\varphi_{1}-\varphi_{2}\right\|_{\alpha}, \quad t \in[0, T] .
$$

Proof. Proof of (ii). Let $x^{1}:=x\left(., \varphi_{1}\right), x^{2}:=x\left(., \varphi_{2}\right), T>0$ and $M>1$ such that $\sup \{\|T(t)\|, t \in$ $[0, T]\} \leq M$. For $t \in[0, T]$, we have

$$
\begin{aligned}
\left\|\mathrm{U}(\mathrm{t})\left(\varphi_{1}\right)-\mathrm{U}(\mathrm{t})\left(\varphi_{2}\right)\right\|_{\alpha} & =\left\|x_{\mathrm{t}}^{1}-x_{\mathrm{t}}^{2}\right\|_{\alpha} \\
& =\sup _{-r \leq \theta \leq 0}\left|x^{1}(\mathrm{t}+\theta)-x^{2}(\mathrm{t}+\theta)\right|_{\alpha} \\
& \leq\left(M+M L_{g}\right)\left\|\varphi_{1}-\varphi_{2}\right\|_{\alpha}+\mathrm{L}_{g} \sup _{-r \leq \theta \leq 0}\left\|x_{\mathrm{t}+\theta}^{1}-x_{\mathrm{t}+\theta}^{2}\right\|_{\alpha} \\
& +M L_{f} \int_{0}^{t}\left\|x_{s}^{1}-x_{s}^{2}\right\|_{\alpha} \mathrm{ds} .
\end{aligned}
$$

Letting $t \in[0, r]$. Then, for $\theta \in[-r, 0]$ such that $t+\theta \geq 0$, we have

$$
\begin{aligned}
\left\|x_{\mathrm{t}+\theta}^{1}-x_{\mathrm{t}+\theta}^{2}\right\|_{\alpha} & =\sup _{-r \leq \tau \leq 0}\left|x^{1}(\mathrm{t}+\theta+\tau)-x^{2}(\mathrm{t}+\theta+\tau)\right|_{\alpha} \\
& =\sup _{-r+\mathrm{t}+\theta \leq \tau \leq \mathrm{t}+\theta}\left|x^{1}(\tau)-x^{2}(\tau)\right|_{\alpha} \\
& =\max \left\{\left\|\varphi_{1}-\varphi_{2}\right\|_{\alpha}, \sup _{0 \leq \tau \leq \mathrm{t}+\theta}\left|\chi^{1}(\tau)-\chi^{2}(\tau)\right|_{\alpha}\right\} \\
& \leq\left\|\varphi_{1}-\varphi_{2}\right\|_{\alpha}+\left\|x_{t}^{1}-x_{\mathrm{t}}^{2}\right\|_{\alpha} .
\end{aligned}
$$

Then,

$$
\left\|x_{t}^{1}-x_{t}^{2}\right\|_{\alpha} \leq\left(\frac{M+M L_{g}+1}{1-L_{g}}\right)\left\|\varphi_{1}-\varphi_{2}\right\|_{\alpha}+\frac{M L_{f}}{1-L_{g}} \int_{0}^{t}\left\|x_{s}^{1}-\chi_{s}^{2}\right\|_{\alpha} \mathrm{ds} .
$$

Using Gronwall's lemma, we obtain

$$
\left\|x_{t}^{1}-x_{t}^{2}\right\|_{\alpha} \leq\left(\frac{M+M L_{g}+1}{1-L_{g}}\right) e^{\frac{M L_{f}}{1-L_{g}} t}\left\|\varphi_{1}-\varphi_{2}\right\|_{\alpha} .
$$

We can repeat the previous argument for $t \in[r, 2 r]$, to see that for every $t \in[r, 2 r]$,

$$
\begin{aligned}
\left\|\mathrm{U}(\mathrm{t})\left(\varphi_{1}\right)-\mathrm{U}(\mathrm{t})\left(\varphi_{2}\right)\right\|_{\alpha} & \leq\|\mathrm{U}(\mathrm{r})\|\left\|\mathrm{U}(\mathrm{t}-\mathrm{r})\left(\varphi_{1}\right)-\mathrm{U}(\mathrm{t}-\mathrm{r})\left(\varphi_{2}\right)\right\|_{\alpha} \\
& \leq\left(\frac{M+M L_{g}+1}{1-\mathrm{L}_{g}}\right)^{2} e^{\frac{M L_{f}}{1-L_{g}}}\left\|\varphi_{1}-\varphi_{2}\right\|_{\alpha} .
\end{aligned}
$$

For $\mathrm{t} \in[2 \mathrm{r}, 3 \mathrm{r}]$

$$
\begin{aligned}
\left\|\mathrm{U}(\mathrm{t})\left(\varphi_{1}\right)-\mathrm{U}(\mathrm{t})\left(\varphi_{2}\right)\right\|_{\alpha} & \leq\|\mathrm{U}(2 r)\|\left\|\mathrm{U}(\mathrm{t}-2 r)\left(\varphi_{1}\right)-\mathrm{U}(\mathrm{t}-2 \mathrm{r})\left(\varphi_{2}\right)\right\|_{\alpha} \\
& \leq\left(\frac{\mathrm{M}+\mathrm{ML}_{\mathrm{g}}+1}{1-\mathrm{L}_{g}}\right)^{3} \mathrm{e}^{\frac{M L_{f}}{1-L_{g}} \mathrm{t}}\left\|\varphi_{1}-\varphi_{2}\right\|_{\alpha} .
\end{aligned}
$$


Inductively, for $t \in[n r,(n+1) r]$ with $n \geq 2$, we obtain

$$
\begin{aligned}
\left\|\mathrm{U}(\mathrm{t})\left(\varphi_{1}\right)-\mathrm{U}(\mathrm{t})\left(\varphi_{2}\right)\right\|_{\alpha} & \leq\|\mathrm{U}(\mathrm{nr})\|\left\|\mathrm{U}(\mathrm{t}-\mathrm{nr})\left(\varphi_{1}\right)-\mathrm{U}(\mathrm{t}-\mathrm{nr})\left(\varphi_{2}\right)\right\|_{\alpha} \\
& \leq\left(\frac{\mathrm{M}+\mathrm{ML}_{\mathrm{g}}+1}{1-\mathrm{L}_{\mathrm{g}}}\right)^{\mathrm{n}+1} \mathrm{e}^{\frac{M \mathrm{~L}_{\mathrm{f}}}{1-\mathrm{L}_{\mathrm{g}}}}\left\|\varphi_{1}-\varphi_{2}\right\|_{\alpha} .
\end{aligned}
$$

Consequently, the estimate (12) is true. This ends the proof.

In what follows, we study the stability of an equilibrium of the following autonomous equation:

$$
\left\{\begin{array}{l}
\frac{d}{d t}\left[D\left(x_{t}\right)-G\left(x_{t}\right)\right]=-A\left[D\left(x_{t}\right)-G\left(x_{t}\right)\right]+F\left(x_{t}\right) \quad \text { for } t \geq 0 \\
x_{0}=\varphi \in C_{\alpha}
\end{array}\right.
$$

where $F$ and $G$ are Lipschitz continuous on $C_{\alpha}$ with constants respectively $L_{F}$ and $L_{G}$ and $D$ : $\mathrm{C}_{\alpha} \longrightarrow \mathrm{X}_{\alpha}$ is an operator defined by $\mathrm{D} \varphi=\varphi(0)-\mathrm{D}_{0} \varphi$ with $\mathrm{D}_{0}$ a bounded linear operator from $\mathrm{C}_{\alpha}$ into $\mathrm{X}_{\alpha}$ such that $\mathrm{L}_{\mathrm{G}}+\left\|\mathrm{D}_{0}\right\|<1$.

We are now interested by the stability of the equilibriums of Equation (13). By equilibrium, we mean a constant mild solution $x^{*}$ of (13). Without loss of generality, we can assume that $x^{*}=0$ and $\mathrm{G}(0)=\mathrm{F}(0)=0$ :

We need the following assumption.

(H6) $\mathrm{F}$ and $\mathrm{G}$ are Fréchet-differentiable at 0 and $\mathrm{G}^{\prime}(0)=0$.

Let $L=F^{\prime}(0)$. Then, the linearized equation of Eq. (13) around the equilibrium 0 is the following:

$$
\left\{\begin{array}{l}
\frac{d}{d t} D y_{t}=-A D y_{t}+L\left(y_{t}\right) \quad \text { for } t \geq 0 \\
y_{0}=\varphi \in C_{\alpha}
\end{array}\right.
$$

Let $(\mathrm{U}(\mathrm{t}))_{\mathrm{t} \geqslant 0}$ the nonlinear semigroup associated to Eq. (13) and the linear semigroup $(\mathrm{V}(\mathrm{t}))_{\mathrm{t} \geqslant 0}$ associated to the linear equation (14) in the same space $C_{\alpha}$. Then, we have the following result.

Theorem 4.1. Assume that the conditions (HO), (H2), (H4), (H5) and (H6) hold. Then, for every $\mathrm{t} \geqslant 0$ the derivative at zero of $\mathrm{U}(\mathrm{t})$ is $\mathrm{V}(\mathrm{t})$.

The proof of this theorem is based on the following fundamental lemma

Lemma 4.2. Let $\mathrm{H}: \mathrm{C}_{\alpha} \longrightarrow \mathrm{X}_{\alpha}$ be a continuous function such that there exists $0<\mu_{0}<1$ satisfying

$$
\left|\mathrm{H}\left(\varphi_{1}\right)-\mathrm{H}\left(\varphi_{2}\right)\right|_{\alpha} \leqslant \mu_{0}\left\|\varphi_{1}-\varphi_{2}\right\|_{\alpha}
$$

Let $\varphi \in \mathrm{C}_{\alpha}$ and $\mathrm{h}:\left[0,+\infty\left[\longrightarrow \mathrm{X}_{\alpha}\right.\right.$ be a continuous function. Suppose that there exist continuous functions $x, y:\left[-r,+\infty\left[\longrightarrow \mathrm{X}_{\alpha}\right.\right.$ such that

$$
\left\{\begin{array}{l}
x(t)-y(t)=H\left(x_{t}\right)-H\left(y_{t}\right)+h(t), \quad t \geq 0 \\
x_{0}=y_{0}=\varphi
\end{array}\right.
$$


Then, for each $0<\mathrm{T} \leq \mathrm{r}$ we have

$$
\left\|x_{t}-y_{t}\right\|_{\alpha} \leqslant \frac{1}{1-\mu_{0}} \sup _{0 \leqslant s \leqslant t}|h(s)|_{\alpha}, \quad t \in[0, T] .
$$

Proof. For $\mathrm{t} \geq 0$, we have

$$
\begin{aligned}
\left\|x_{t}-y_{t}\right\|_{\alpha} & =\sup _{-r \leq \theta \leq 0}|x(t+\theta)-y(t+\theta)|_{\alpha} \\
& =\sup _{t-r \leq s \leq t}|x(s)-y(s)|_{\alpha} \\
& =\sup _{0 \leq s \leq t}|x(s)-y(s)|_{\alpha} \\
& \leq \sup _{0 \leq s \leq t}\left|H\left(x_{s}\right)-H\left(y_{s}\right)\right|_{\alpha}+\sup _{0 \leq s \leq t}|h(s)|_{\alpha} \\
& \leq \mu_{0} \sup _{0 \leq s \leq t}\left\|x_{s}-y_{s}\right\|_{\alpha}+\sup _{0 \leq s \leq t}|h(s)|_{\alpha} \\
& =\mu_{0}\left\|x_{t}-y_{t}\right\|_{\alpha}+\sup _{0 \leq s \leq t}|h(s)|_{\alpha}
\end{aligned}
$$

Then $\left\|x_{t}-y_{t}\right\|_{\alpha} \leqslant \frac{1}{1-\mu_{0}} \sup _{0 \leqslant s \leqslant t}|h(s)|_{\alpha}$

Proof. (of Theorem 4.1) It suffices to show that for each $\varphi \in \mathrm{C}_{\alpha}, \mathrm{t} \geq 0$ and $\varepsilon>0$, there exists $\delta>0$ such that

$$
\|\mathrm{U}(\mathrm{t}) \varphi-\mathrm{V}(\mathrm{t}) \varphi\|_{\alpha} \leqslant \varepsilon\|\varphi\|_{\alpha}, \text { for }\|\varphi\|_{\alpha} \leqslant \delta
$$

Let $\mathrm{t} \geq 0$ be fixed and $\varphi \in \mathrm{C}_{\alpha}$. We have

$$
\begin{aligned}
(\mathrm{D} & -\mathrm{G})(\mathrm{U}(\mathrm{t}) \varphi)-\mathrm{D}(\mathrm{V}(\mathrm{t}) \varphi) \\
& =\int_{0}^{\mathrm{t}} \mathrm{T}(\mathrm{t}-\mathrm{s})[\mathrm{F}(\mathrm{U}(\mathrm{s}) \varphi)-\mathrm{F}(\mathrm{V}(\mathrm{s}) \varphi)] \mathrm{ds}-\mathrm{T}(\mathrm{t}) \mathrm{G}(\varphi) \\
& +\int_{0}^{\mathrm{t}} \mathrm{T}(\mathrm{t}-\mathrm{s})[\mathrm{F}(\mathrm{V}(\mathrm{s}) \varphi)-\mathrm{L}(\mathrm{V}(\mathrm{s}) \varphi)] \mathrm{d} s
\end{aligned}
$$

Then,

$$
\begin{aligned}
(\mathrm{D} & -\mathrm{G})(\mathrm{U}(\mathrm{t}) \varphi)-(\mathrm{D}-\mathrm{G})(\mathrm{V}(\mathrm{t}) \varphi) \\
& =\mathrm{G}(\mathrm{V}(\mathrm{t}) \varphi)-\mathrm{T}(\mathrm{t}) \mathrm{G}(\varphi)+\int_{0}^{\mathrm{t}} \mathrm{T}(\mathrm{t}-\mathrm{s})[\mathrm{F}(\mathrm{U}(\mathrm{s}) \varphi)-\mathrm{F}(\mathrm{V}(\mathrm{s}) \varphi)] \mathrm{ds} \\
& +\int_{0}^{\mathrm{t}} \mathrm{T}(\mathrm{t}-\mathrm{s})[\mathrm{F}(\mathrm{V}(\mathrm{s}) \varphi)-\mathrm{L}(\mathrm{V}(\mathrm{s}) \varphi)] \mathrm{ds}
\end{aligned}
$$

Let $x, y:\left[-r,+\infty\left[\longrightarrow X_{\alpha}\right.\right.$ and $h:\left[0,+\infty\left[\longrightarrow X_{\alpha}\right.\right.$ be defined by

$$
x(t)=\left\{\begin{array}{ll}
(\mathrm{U}(\mathrm{t}) \varphi)(0) & \text { if } \mathrm{t} \in[0,+\infty[ \\
\varphi(\mathrm{t}) & \text { if } \mathrm{t} \in[-\mathrm{r}, 0]
\end{array} \quad \mathrm{y}(\mathrm{t})= \begin{cases}(\mathrm{V}(\mathrm{t}) \varphi)(0) & \text { if } \mathrm{t} \in[0,+\infty[ \\
\varphi(\mathrm{t}) & \text { if } \mathrm{t} \in[-\mathrm{r}, 0]\end{cases}\right.
$$


and

$$
\begin{aligned}
h(t) & =G(V(t) \varphi)-T(t) G(\varphi)+\int_{0}^{t} T(t-s)[F(U(s) \varphi)-F(V(s) \varphi)] d s \\
& +\int_{0}^{t} T(t-s)[F(V(s) \varphi)-L(V(s) \varphi)] d s
\end{aligned}
$$

Then,

$$
\left\{\begin{array}{l}
(D-G)\left(x_{t}\right)-(D-G)\left(y_{t}\right)=h(t), \quad t \geq 0 \\
x_{0}=y_{0}=\varphi
\end{array}\right.
$$

which is equivalent to

$$
\left\{\begin{array}{l}
x(t)-y(t)=\left(D_{0}+G\right)\left(x_{t}\right)-\left(D_{0}+G\right)\left(y_{t}\right)+h(t), \quad t \geq 0 \\
x_{0}=y_{0}=\varphi
\end{array}\right.
$$

Using Lemma (4.2), we obtain

$$
\left\|x_{t}-y_{t}\right\|_{\alpha} \leqslant \frac{1}{1-\left(L_{G}+\left\|D_{0}\right\|\right)} \sup _{0 \leqslant s \leqslant t}|h(s)|_{\alpha}, \quad t \geq 0 .
$$

By virtue of the continuous differentiability of $G$ and $F$ at 0 , we deduce that for $\varepsilon>0$, there exists $\delta>0$ such that

$$
|\mathrm{G}(\mathrm{V}(\mathrm{t}) \varphi)-\mathrm{T}(\mathrm{t}) \mathrm{G}(\varphi)|_{\alpha} \leqslant \varepsilon\|\varphi\|_{\alpha} \text { for }\|\varphi\|_{\alpha} \leqslant \delta
$$

and

$$
M_{\alpha} \int_{0}^{t}|\mathrm{~F}(\mathrm{~V}(\mathrm{~s}) \varphi)-\mathrm{L}(\mathrm{V}(\mathrm{s}) \varphi)| \frac{\mathrm{d} s}{(\mathrm{t}-\mathrm{s})^{\alpha}} \leqslant \varepsilon\|\varphi\|_{\alpha} \text { for }\|\varphi\|_{\alpha} \leqslant \delta .
$$

Then, for $\|\varphi\|_{\alpha} \leqslant \delta$,

$$
|h(t)|_{\alpha} \leq 2 \varepsilon\|\varphi\|_{\alpha}+M_{\alpha} L_{F} \int_{0}^{t}\|\mathrm{U}(s) \varphi-V(s) \varphi\|_{\alpha} \frac{d s}{(t-s)^{\alpha}},
$$

Since for $s \in[0, t]$ and $t \in[0, r]$,

$$
\begin{aligned}
\|\mathrm{U}(\mathrm{s}) \varphi-\mathrm{V}(\mathrm{s}) \varphi\|_{\alpha} & =\sup _{-r \leq \theta \leq 0}\left|x_{s}(\theta)-y_{s}(\theta)\right|_{\alpha} \\
& =\sup _{-r+s \leq \tau \leq s}|x(\tau)-y(\tau)|_{\alpha} \\
& =\sup _{0 \leq \tau \leq s}|x(\tau)-y(\tau)|_{\alpha} \\
& \leq \sup _{0 \leq \tau \leq t}|x(\tau)-y(\tau)|_{\alpha} \\
& =\|\mathrm{U}(\mathrm{t}) \varphi-\mathrm{V}(\mathrm{t}) \varphi\|_{\alpha} .
\end{aligned}
$$

Then for $t \in[0, r]$ fixed

$$
\|\mathrm{U}(\mathrm{t}) \varphi-\mathrm{V}(\mathrm{t}) \varphi\|_{\alpha} \leq \frac{2 \varepsilon\|\varphi\|_{\alpha}}{1-\left(\mathrm{L}_{\mathrm{G}}+\left\|\mathrm{D}_{\mathrm{O}}\right\|\right)}+\frac{\mathrm{M}_{\alpha} \mathrm{L}_{\mathrm{F}}}{1-\left(\mathrm{L}_{\mathrm{G}}+\left\|\mathrm{D}_{\mathrm{O}}\right\|\right)} \int_{0}^{\mathrm{t}} \frac{\|\mathrm{U}(\mathrm{s}) \varphi-\mathrm{V}(\mathrm{s}) \varphi\|_{\alpha}}{(\mathrm{t}-\mathrm{s})^{\alpha}} \mathrm{ds}
$$


Using Gronwall's lemma, we obtain

$$
\|\mathrm{U}(\mathrm{t}) \varphi-\mathrm{V}(\mathrm{t}) \varphi\|_{\alpha} \leq \frac{2 \varepsilon\|\varphi\|_{\alpha}}{1-\left(\mathrm{L}_{\mathrm{G}}+\left\|\mathrm{D}_{0}\right\|\right)} \exp \left(\frac{\mathrm{M}_{\alpha} \mathrm{L}_{\mathrm{F}} \mathrm{t}^{1-\alpha}}{\left(1-\left(\mathrm{L}_{\mathrm{G}}+\left\|\mathrm{D}_{\mathrm{o}}\right\|\right)\right)(1-\alpha)}\right)
$$

for $\|\varphi\|_{\alpha} \leqslant \delta$. We conclude that $\mathrm{U}(\mathrm{t})$ is differentiable at 0 , for each $\mathrm{t} \in[0, T]$ and $\mathrm{D}_{\varphi} \mathrm{U}(\mathrm{t})(0)=$ $\mathrm{V}(\mathrm{t})$.

Now, suppose that $\mathrm{t} \in[\mathrm{T}, 2 \mathrm{~T}]$ fixed. It follows that, for $\max \left\{\|\varphi\|_{\alpha},\|\mathrm{U}(\mathrm{t}-\mathrm{T})(\varphi)\|_{\alpha}\right\} \leq \delta_{0}$, where $\delta_{0}>0$ is small enough

$$
\begin{aligned}
\|\mathrm{U}(\mathrm{t}) \varphi-\mathrm{V}(\mathrm{t}) \varphi\|_{\alpha} \leq & \|\mathrm{U}(\mathrm{T}) \mathrm{U}(\mathrm{t}-\mathrm{T})(\varphi)-\mathrm{V}(\mathrm{T}) \mathrm{U}(\mathrm{t}-\mathrm{T})(\varphi)\|_{\alpha} \\
& +\|\mathrm{V}(\mathrm{T})\|\|\mathrm{U}(\mathrm{t}-\mathrm{T})(\varphi)-\mathrm{V}(\mathrm{t}-\mathrm{T})(\varphi)\|_{\alpha} \\
\leq & \varepsilon\|\varphi\|_{\alpha} .
\end{aligned}
$$

By steps, we conclude that $\mathrm{U}(\mathrm{t})$ is differentiable at 0 , for each $t \geq 0$ and $\mathrm{D}_{\varphi} \mathrm{U}(\mathrm{t})(0)=\mathrm{V}(\mathrm{t})$.

Theorem 4.2. Under the assumption as in the Theorem (4.1), if the zero equi- librium of $(\mathrm{V}(\mathrm{t}))_{\mathrm{t} \geq 0}$ is exponentially stable, then the zero equilibrium of $(\mathrm{U}(\mathrm{t}))_{\mathrm{t} \geq 0}$ is locally exponentially stable, in the sense that there exist $\delta>0, \mu>0$ and $\mathrm{k} \geq 1$ such that

$$
\|\mathrm{U}(\mathrm{t})(\varphi)\|_{\alpha} \leq k e^{-\mu \mathrm{t}}\|\varphi\|_{\alpha} \quad \text { for } \mathrm{t} \geq 0 \text { and } \varphi \in \mathrm{C}_{\alpha} \text { with }\|\varphi\|_{\alpha} \leq \delta .
$$

Moreover, if $\mathrm{C}_{\alpha}$ can be decomposed as $\mathrm{C}_{\alpha}=\mathcal{H}_{1} \oplus \mathcal{H}_{2}$ where $\mathcal{H}_{i}$ are $\mathrm{V}$-invariant subspaces of $\mathrm{C}_{\alpha}, \mathcal{H}_{1}$ is fnite-dimensional and with

$$
\omega=\lim _{h \rightarrow \infty} \frac{1}{h} \log \left\|V(h) / \mathcal{H}_{2}\right\|_{\alpha}
$$

we have

$$
\inf \left\{|\lambda|: \lambda \in \sigma\left(\mathrm{V}(\mathrm{t}) / \mathcal{H}_{1}\right)\right\}>e^{\omega t},
$$

then, the zero equilibrium of $(\mathrm{U}(\mathrm{t}))_{\mathrm{t} \geq 0}$ is not stable, in the sense that there exist $\varepsilon>0$ and a sequence $\left(\varphi_{\mathfrak{n}}\right)_{n}$ converging to 0 and a sequence $\left(t_{n}\right)_{n}$ of positive reel numbers such that $\left\|\mathrm{U}\left(t_{n}\right) \varphi_{n}\right\|_{\alpha}>$ $\varepsilon$.

The proof of this theorem is based on Proposition 4.1, Theorem 4.1 and the following result.

Theorem 4.3. (Desch and Schappacher [13]). Let $(\mathrm{V}(\mathrm{t}))_{\mathrm{t} \geq 0}$ be a nonlinear strongly continuous semigroup on a subset $\Omega$ of a Banach space $\mathrm{Z}$. Assume that $\mathrm{x}_{0} \in \Omega$ is an equilibrium of $(\mathrm{V}(\mathrm{t}))_{\mathrm{t} \geq 0}$ such that $\mathrm{V}(\mathrm{t})$ is Fréchet-differentiable at $\mathrm{x}_{0}$ for each $\mathrm{t} \geq 0$, with $\mathrm{W}(\mathrm{t})$ the derivative at $\mathrm{x}_{0}$ of $\mathrm{V}(\mathrm{t}), \mathrm{t} \geq 0$. Then, $(\mathrm{W}(\mathrm{t}))_{\mathrm{t} \geq 0}$ is a strongly continuous semigroup of bounded linear operators on $\mathrm{Z}$ and, if the zero equilibrium of $(\mathrm{W}(\mathrm{t}))_{\mathrm{t} \geq 0}$ is exponentially stable, then the equilibrium $\mathrm{x}_{0}$ of $(\mathrm{V}(\mathrm{t}))_{\mathrm{t} \geq 0}$ is locally exponentially stable. Moreover, if $\mathbf{Z}$ can be decomposed as $\mathrm{Z}=\mathrm{Z}_{1} \oplus \mathrm{Z}_{2}$ where $Z_{i}$ are $\mathrm{W}$-invariant subspaces of $\mathbf{Z}$ and $\mathbf{Z}_{1}$ is fnite-dimensional and with

$$
\omega=\lim _{h \rightarrow \infty} \frac{1}{h} \log \left\|W(h) / Z_{2}\right\|,
$$


we have

$$
\inf \left\{|\lambda|: \lambda \in \sigma\left(W(t) / Z_{1}\right)\right\}>e^{\omega t},
$$

then, the zero equilibrium $\mathrm{x}_{0}$ of $(\mathrm{V}(\mathrm{t}))_{\mathrm{t} \geq 0}$ is not stable, in the sense that there exist $\varepsilon>0$ and a sequence $\left(\mathrm{x}_{\mathrm{n}}\right)_{\mathrm{n}}$ converging to $\mathrm{x}_{0}$ and a sequence $\left(\mathrm{t}_{\mathrm{n}}\right)_{\mathrm{n}}$ of positive reel numbers such that $\| \mathrm{V}\left(\mathrm{t}_{\mathrm{n}}\right) \mathrm{x}_{\mathrm{n}}-$ $x_{0} \|>\varepsilon$.

In the following, we will concentrate our study on the linear equation (14). Let $\left(A_{V}, D\left(A_{V}\right)\right)$ be the generator of the semigroup $(V(t))_{t \geq 0}$ on $C_{\alpha}$. We have the result

Theorem 4.4. [4] Assume that the conditions (Ho), (H2), (H4), (H5) and (H6) hold. Then, the operator $\left(A_{V}, \mathrm{D}\left(A_{V}\right)\right)$ is given by

$$
\left\{\begin{array}{l}
\mathrm{D}\left(\mathrm{A}_{\mathrm{V}}\right)=\left\{\varphi \in \mathrm{C}_{\alpha}, \varphi^{\prime} \in \mathrm{C}_{\alpha}, \mathrm{D}(\varphi) \in \mathrm{D}(\mathrm{A}) \text { and } \mathrm{D}\left(\varphi^{\prime}\right)=-\mathrm{AD}(\varphi)+\mathrm{L}(\varphi)\right\} \\
\mathrm{A}_{\mathrm{V}} \varphi=\varphi^{\prime}, \quad \varphi \in \mathrm{D}\left(\mathrm{A}_{\mathrm{V}}\right)
\end{array}\right.
$$

Let $C$ be the space of continuous functions from $[-r, 0]$ into $X$ provided with the uniform norm topology and let

$$
\mathrm{C}_{\mathrm{D}}=\{\varphi \in \mathrm{C}: \mathrm{D}(\varphi)=0\} \text {. }
$$

Definition 4.3. [22] D is said to be stable if the zero solution of the difference equation

$$
\left\{\begin{array}{l}
D\left(y_{t}\right)=0, \quad t \geq 0 \\
y_{0}=\varphi \in C_{D}
\end{array}\right.
$$

is exponentially stable.

Lemma 4.4. [4] If $\mathrm{D}$ is stable, then there exist positive constants $\mathrm{a}, \mathrm{b}, \mathrm{c}$ and $\mathrm{d}$ such that for any $\varepsilon \in] 0, \mathrm{r}]$ sufficiently small and any continuous function $\mathrm{h}$ from $[0,+\infty[$ into $\mathrm{X}$, the solution $v$ of the equation

$$
\mathrm{D}\left(v_{\mathrm{t}}\right)=\mathrm{h}(\mathrm{t}), \quad \mathrm{t} \geq 0,
$$

satisfies the inequality

$$
\left\|v_{\mathrm{t}}\right\| \leq \mathrm{e}^{-\mathrm{a}(\mathrm{t}-\varepsilon)}\left[\mathrm{b}\left\|v_{0}\right\|+\mathrm{c} \sup _{0 \leq s \leq \varepsilon}|\mathrm{h}(\mathrm{s})|\right]+\mathrm{d} \sup _{\max (\varepsilon, \mathrm{t}-\mathrm{r}) \leq \mathrm{s} \leq \mathrm{t}}|\mathrm{h}(\mathrm{s})|, \mathrm{t} \geq \varepsilon .
$$

The estimate (15) is very interesting because, if $|\mathrm{h}(\mathrm{s})|$ is bounded on $[0,+\infty[$, then the ultimate bound on $v_{t}$ as $t \rightarrow+\infty$ is determined by the bound on $|h(s)|$ for $s$ in the delay interval $[t-r, t]$ as $t \rightarrow+\infty$.

Proposition 4.5. [20] Let $\mathrm{D}(\varphi)=\sum_{\mathrm{k}=0}^{\mathrm{p}} \mathrm{a}_{\mathrm{k}} \varphi\left(-\mathrm{r}_{\mathrm{k}}\right)$. Then, D is stable iff $\sum_{\mathrm{k}=0}^{p}\left|\mathrm{a}_{\mathrm{k}}\right|<1$.

In the sequel, we assume that 
(H7) The operator D is stable.

Theorem 4.5. 4] Assume that (HO), (H1), (H2), (H4), (H5) and (H7) hold. Then the semigroup $(\mathrm{U}(\mathrm{t}))_{\mathrm{t} \geq 0}$ can be decomposed as follows

$$
\mathrm{U}(\mathrm{t})=\mathrm{U}_{1}(\mathrm{t})+\mathrm{U}_{2}(\mathrm{t}) \quad \text { for } \mathrm{t} \geq 0,
$$

where $\mathrm{U}_{1}(\mathrm{t})$ is an exponentially stable semigroup on $\mathrm{C}_{\alpha}$ and $\mathrm{U}_{2}(\mathrm{t})$ is compact on $\mathrm{C}_{\alpha}$ for every $\mathrm{t}>0$.

Let $(\mathrm{Y},\|\|$.$) be a Banach space. For a bounded linear operator B in \mathrm{Y}$, we define

$$
\|\mathrm{B}\|_{\text {ess }}:=\inf \{c>0: \chi(B(H)) \leq c \chi(H) \text {, for every bounded set } \mathrm{H} \text { of } Y\},
$$

where $\chi($.$) denotes the measure of noncompactness in Y$.

The essential growth bound of $(V(t))_{t \geq 0}$ in $C_{\alpha}$ is given by

$$
\omega_{\text {ess }}(V):=\inf _{t>0} \frac{1}{t} \log \|V(t)\|_{\text {ess }} .
$$

It follows from Theorem 4.5, that

$$
\omega_{\text {ess }}(\mathrm{V})<0 \text {. }
$$

Let

$$
\omega_{0}(V):=\inf _{t>0} \frac{1}{t} \log \|V(t)\|_{\alpha}
$$

be the growth bound of $(V(t))_{t \geq 0}$ in $C_{\alpha}$. Then, it is well known (see [14]) that

$$
\omega_{0}(V)=\max \left\{\omega_{e s s}(V), s^{\prime}\left(A_{V}\right)\right\}
$$

where

$$
s^{\prime}\left(A_{V}\right)=\sup \left\{\operatorname{Re} \lambda: \lambda \in \sigma\left(A_{V}\right) \backslash \sigma_{e s s}\left(A_{V}\right)\right\}
$$

and $\sigma_{\text {ess }}\left(A_{V}\right)$ is the essential spectrum of $A_{V}$. Consequently, the stability of $(V(t))_{t \geq 0}$ is completely determined by $s^{\prime}\left(A_{V}\right)$. Note that $\sigma\left(A_{V}\right) \backslash \sigma_{e s s}\left(A_{V}\right)$ contains a finite number of eigenvalues of $A_{V}$.

We say that $\lambda \in \mathbb{C}$ is a characteristic value of Equation (14) if there exists a nonzero $x \in D(\Delta(\lambda)) \backslash\{0\}$ such that $\Delta(\lambda) x=0$, where $\Delta(\lambda)$ is defined by

$$
\Delta(\lambda):=\lambda \mathrm{D}\left(e^{\lambda} \cdot \mathrm{I}\right)+\mathrm{AD}\left(e^{\lambda} \cdot \mathrm{I}\right)-\mathrm{L}\left(e^{\lambda \cdot} \mathrm{I}\right),
$$

and the domain $\mathrm{D}(\Delta(\lambda))$ is given by

$$
\mathrm{D}(\Delta(\lambda)):=\left\{x \in \mathrm{X}_{\alpha}: \mathrm{D}\left(e^{\lambda} \cdot \mathrm{x}\right) \in \mathrm{D}(\mathrm{A}) \text { and } \mathrm{AD}\left(e^{\lambda} \cdot x\right)-\mathrm{L}\left(e^{\lambda} \cdot x\right) \in \mathrm{X}_{\alpha}\right\} .
$$

Consequently, we deduce the following theorem.

Theorem 4.6. 4] Assume that (HO), (H1), (H2), (H4), (H5),(H6) and (H7) hold. Then, the following assertions hold 
(i) $\lambda$ is an eigenvalue of $A_{\vee}$ iff $\lambda$ is a characteristic value of Equation (14).

(ii) If $\mathrm{s}^{\prime}\left(\mathrm{A}_{\mathrm{V}}\right)<0$, then $(\mathrm{V}(\mathrm{t}))_{\mathrm{t} \geq 0}$ is exponentially stable and consequently, the zero equilibrium of $(\mathrm{U}(\mathrm{t}))_{\mathrm{t} \geq 0}$ is locally exponentially stable.

(iii) If $\mathrm{s}^{\prime}\left(\mathrm{A}_{\mathrm{V}}\right)=0$, then there exists $\varphi \in \mathrm{C}_{\alpha}, \varphi \neq 0$, such that $\|\mathrm{V}(\mathrm{t}) \varphi\|_{\alpha}=\|\varphi\|_{\alpha}$, for $\mathrm{t} \geq 0$.

(iv) If $\mathrm{s}^{\prime}\left(\mathrm{A}_{\mathrm{V}}\right)>0$, then there exists $\varphi \in \mathrm{C}_{\alpha}$ such that $\|\mathrm{V}(\mathrm{t}) \varphi\|_{\alpha} \rightarrow+\infty$ as $\mathrm{t} \rightarrow+\infty$ and consequently, the zero equilibrium of $(\mathrm{U}(\mathrm{t}))_{\mathrm{t} \geq 0}$ is instable.

(v) Assume that $\mathrm{s}^{\prime}\left(\mathrm{A}_{\mathrm{V}}\right) \leq 0$ and let $\mathrm{s}_{\mathrm{O}}\left(\mathrm{A}_{\mathrm{V}}\right):=\left\{\lambda \in \operatorname{P\sigma }\left(\mathrm{A}_{\mathrm{V}}\right): \operatorname{Re} \lambda=0\right\}$. If each $\lambda$ in $\mathrm{s}_{0}\left(\mathrm{~A}_{\mathrm{V}}\right)$ is a pole of order 1 of the resolvent operator of $A_{V}$, then $(\mathrm{V}(\mathrm{t}))_{\mathrm{t} \geq 0}$ is stable in the sense that there exists a positive constant $M$ such that $\|\mathrm{V}(\mathrm{t})\|_{\alpha} \leq \mathrm{M}$, for all $\mathrm{t} \geq 0$.

\section{Example}

To apply our theoretical results, we consider the following model of partial differential equation with delay

$$
\left\{\begin{array}{r}
\frac{\partial}{\partial t}\left[v(t, x)-q v(t-r, x)+g\left(\frac{\partial}{\partial x} v(t-r, x)\right)\right]=\frac{\partial^{2}}{\partial x^{2}}[v(t, x)-q v(t-r, x) \\
\left.+g\left(\frac{\partial}{\partial x} v(t-r, x)\right)\right]+f\left(v(t-r, x), \frac{\partial}{\partial x}[v(t, x)-q v(t-r, x)]\right) \\
\quad \text { for } t \geq 0 \text { and } x \in[0, \pi], \\
v(t, 0)-q v(t-r, 0)=v(t, \pi)-q v(t-r, \pi)=0 \text { for } t \geq 0, \\
v(\theta, x)=v_{0}(\theta, x) \text { for }-r \leq \theta \leq 0 \text { and } x \in[0, \pi]
\end{array}\right.
$$

where $q, r$ are positive constants, $u_{0} \in C([-r, 0] \times[0, \pi] ; \mathbb{R})$ and $f, g$ are Lipschitz continuous functions. Let $X:=L^{2}([0, \pi] ; \mathbb{R})$ equipped with the $L^{2}$-norm $\|\cdot\|_{2}$. Consider the operator $A: D(A) \subset$ $X \rightarrow X$ defined by $A y=-y^{\prime \prime}$ with domain $D(A)=H^{2}(0, \pi) \cap H_{0}^{1}(0, \pi)$. The spectrum $\sigma(-A)$ of $-A$ is equal to the point spectrum $\sigma_{p}(-A)$ and is given by $\sigma(-A)=\sigma_{p}(-A)=\left\{-n^{2}: n \geq 1\right\}$ and the associated eigenfunctions $\left(e_{n}\right)_{n \geq 1}$ are given by $e_{n}(s)=\sqrt{\frac{2}{\pi}} \sin n s, s \in[0, \pi]$. Then $A y=\sum_{n=1}^{\infty} n^{2}\left(y, e_{n}\right) e_{n}, y \in D(A)$. For each $y \in D\left(A^{\frac{1}{2}}\right):=\left\{y \in X: \sum_{n=1}^{\infty} n\left(y, e_{n}\right) e_{n} \in X\right\}$ the operator $A^{\frac{1}{2}}$ is given by $A^{\frac{1}{2}} y=\sum_{n=1}^{\infty} n\left(y, e_{n}\right) e_{n}$.

It is well known that $-A$ is the infinitesimal generator of an analytic semigroup $(T(t))_{t \geq 0}$ on 
$X$ given by $T(t) x=\sum_{n=1}^{\infty} e^{-n^{2} t}\left(x, e_{n}\right) e_{n}, x \in X$. It follows that $(T(t))_{t \geq 0}$ is a compact semigroup on $X$ and $0 \in \rho(A)$. This implies that the Assumption (H0) and (H1) are satisfied.

Lemma 5.1. 277 If $Y \in D\left(A^{\frac{1}{2}}\right)$, then $Y$ is absolutely continuous, $Y^{\prime} \in X$ and $\left\|Y^{\prime}\right\|=\left\|A^{\frac{1}{2}} Y\right\|$.

Let $\mathrm{G}: \mathrm{C}_{\frac{1}{2}} \rightarrow \mathrm{X}$ be defined by

$$
\mathrm{G}(\varphi)(x)=q \varphi(-r)(x)-g\left(\frac{\partial}{\partial x} \varphi(-r)(x)\right) \quad \text { for } \varphi \in C_{\frac{1}{2}} \text { and } x \in[0, \pi]
$$

and $\mathrm{F}: \mathrm{C}_{\frac{1}{2}} \rightarrow \mathrm{X}$ be defined by

$$
F(\varphi)(x)=f\left(\varphi(-r)(x), \frac{\partial}{\partial x}[\varphi(0)(x)-q \varphi(-r)(x)]\right) \text { for } \varphi \in C_{\frac{1}{2}} \text { and } x \in[0, \pi] .
$$

Lemma 5.2. 44, 27] $\mathrm{F}$ and $\mathrm{G}$ are Lipschitz continuous from $\mathrm{C}_{\frac{1}{2}}$ into $\mathrm{X}$.

Let $x(t)=v(t,$.$) for t \geq 0$ and $\varphi(\theta)=v_{0}(\theta,$.$) for \theta \in[-r, 0]$. Then, Eq. (16) takes the following abstract form

$$
\left\{\begin{array}{l}
\frac{d}{d t}\left(x(t)-G\left(t, x_{t}\right)\right)=-A\left(x(t)-G\left(t, x_{t}\right)\right)+F\left(t, x_{t}\right) \text { for } t \geq 0, \\
x_{0}=\varphi .
\end{array}\right.
$$

Consequently, we have the existence and uniqueness of the mild solution of Eq.(16). Let $v_{0} \in \mathrm{C}_{\frac{1}{2}}$ such that

(a) $v_{0}(0,)-.q v_{0}(-r,)+.g\left(\frac{\partial}{\partial x} v_{0}(-r,).\right) \in H^{2}[0, \pi] \cap H_{0}^{1}[0, \pi]$ and $\frac{\partial}{\partial \theta} v_{0} \in C_{\frac{1}{2}}$,

(b) $\frac{\partial}{\partial \theta} v_{0}(0, x)-q \frac{\partial}{\partial \theta} v_{0}(-r, x)+g^{\prime}\left(\frac{\partial}{\partial x} v_{0}(-r, x)\right) \frac{\partial^{2}}{\partial x \partial \theta} v_{0}(-r, x)$

$$
\begin{aligned}
& =-A\left[v_{0}(0, x)-q v_{0}(-r, x)+g\left(\frac{\partial}{\partial x} v_{0}(-r, x)\right)\right] \\
& +f\left(v_{0}(-r, x), \frac{\partial}{\partial x}\left[v_{0}(0, x)-q v_{0}(-r, x)\right]\right) \text { for } x \in[0, \pi]
\end{aligned}
$$

We deduce that all assumptions of Theorem 3.1 are satisfied. Hence every mild solution of Eq. (16) is a strict solution.

In the sequel, we assume that $0<\mathrm{q}<1$ : This means that the operator $\mathrm{D}$ is stable. We also assume that $f$ and $g$ are continuously differentiable and $f(0,0)=0, g(0)=0$ and $g^{\prime}(0)=0$. Which implies that zero is a solution of 16 and the linearized equation at zero of Equation (16) has the following form

$$
\left\{\begin{array}{l}
\frac{\partial}{\partial t}[v(t, x)-q v(t-r, x)]=\frac{\partial^{2}}{\partial x^{2}}[v(t, x)-q v(t-r, x)] \\
\quad+a v(t-r, x)+b \frac{\partial}{\partial x}[v(t, x)-q v(t-r, x)] \text { for } t \geq 0 \text { and } x \in[0, \pi] \\
v(t, 0)-q v(t-r, 0)=v(t, \pi)-q v(t-r, \pi)=0 \text { for } t \geq 0 \\
v(\theta, x)=v_{0}(\theta, x) \text { for }-r \leq \theta \leq 0 \text { and } x \in[0, \pi]
\end{array}\right.
$$


We obtain a region of stability of Equation (18) as a function of parameters $a, b$ and $q$.

Lemma 5.3. The spectrum $\sigma(\widetilde{A})$ of the operator $\widetilde{A}=\frac{\partial^{2}}{\partial x^{2}}+b \frac{\partial}{\partial x}$ is equal to the point spectrum $\sigma_{p}(\widetilde{A})$ and is given by $\left\{-\mathrm{n}^{2}-\frac{\mathrm{b}^{2}}{4}: \mathrm{n} \geq 1\right\}$.

Theorem 5.1. Suppose that

$$
\mathrm{a}<0 \text { and } 1+\frac{\mathrm{b}^{2}}{4}+\frac{\mathrm{a}}{\mathrm{q}} \geq 0 .
$$

Then, for every $\mathrm{r}>0$, all characteristic values of $E q$. (18) have negative real parts.

Proof. Suppose that $a<0$. Then, the characteristic values of Eq. (18) are determined by the expression

$$
\lambda-\frac{a e^{-\lambda r}}{1-q e^{-\lambda r}}=-n^{2}-\frac{b^{2}}{4}, \quad n \geq 1
$$

Let $K_{n}=n^{2}+\frac{b^{2}}{4}, \quad n \geq 1$. Then, Eq. (19) becomes

$$
e^{\lambda r}\left(\lambda+k_{n}\right)=\lambda q+K_{n} q+a
$$

This implies that

$$
e^{2 \operatorname{Re}(\lambda) r}\left(\left(\operatorname{Re}(\lambda)+K_{n}\right)^{2}+(\operatorname{Im}(\lambda))^{2}=q^{2}\left(\left(\operatorname{Re}(\lambda)+K_{n}+\frac{a}{q}\right)+(\operatorname{Im}(\lambda))^{2}\right) .\right.
$$

On the other hand, under the conditions

$$
a<0 \text { and } 1+\frac{b^{2}}{4}+\frac{a}{q} \geq 0,
$$

we have, for all $n \geq 1$ and $\lambda \in \mathbb{C}$,

$$
\operatorname{Re}(\lambda)+K_{n}>\operatorname{Re}(\lambda)+K_{n}+\frac{a}{q} \geq \operatorname{Re}(\lambda)+1+\frac{b^{2}}{4}+\frac{a}{q} \geq \operatorname{Re}(\lambda) .
$$

Then, if we assume that $\operatorname{Re}(\lambda) \geq 0$, we obtain that

$$
e^{2 \operatorname{Re}(\lambda) r}<q^{2}
$$

which is a contradiction. Then, $\operatorname{Re}(\lambda)<0$.

Remark that the stability result is independent of the delay. Finally, as an immediate consequence of the last theorem, we have the local stability of the zero equilibrium of Equation (16).

Proposition 5.4. Under the same assumptions as in Theorem 5.1, zero equilibrium of Equation (16) is locally exponentially stable.

Received: October 2012. Revised: February 2013. 


\section{References}

[1] M.Adimy and K. Ezzinbi, A class of linear partial neutral functional dierential equations with non- dense domain, Journal of Differential Equations, 147, (1998), 285-332.

[2] M. Adimy and K. Ezzinbi, Existence and linearized stability for partial neutral functional differential equations with nondense domains, Differential Equations and Dynamical Systems, 7, 371-417, (1999).

[3] M. Adimy and K. Ezzinbi, Strict solutions of nonlinear hyperbolic neutral dierential equations, Appl. Math. Letters, 12, 107-112, (1999).

[4] M. Adimy and K. Ezzinbi, Existence and stability in the $\alpha$-norm for partial functional differential equations of neutral type, Annali di Matematica Pura ed Applicata, 185(3), (2006), 437-460.

[5] M. Adimy, H. Bouzahir, K. Ezzinbi, Existence for a class of partial functional differential equations with infinite delay, Nonlinear Analysis, 46, (2001), 91-112.

[6] M. Adimy, H. Bouzahir, K. Ezzinbi, Local existence and stability for some partial functional differential equations with infinite delay, Nonlinear Analysis, 48, (2002), 323-348.

[7] M. Adimy, H. Bouzahir, K. Ezzinbi, Existence and stability for some partial neutral functional differential equations with infinite delay, Journal of Mathematical Analysis and Applications, 294, (2004), 438-461.

[8] M. Adimy, A. Elazzouzi, K. Ezzinbi, Reduction principle and dynamic behaviors for a class of partial functional differential equations, Nonlinear Analysis, 71, (2009), 17091727 .

[9] M. Adimy, K. Ezzinbi, M.Laklach, Existence of solutions for a class of partial neutral differential equations, C. R. Acad. Sci. Paris Sr. I Math. 330, (2000), 957-962.

[10] Banas, J.; Goebel, K.: Measure of Noncompactness in Banach spaces, Lecture Notes in pure and Applied Math, vol. 60, Marcle Dekker, New York, 1980.

[11] M.Muslim, D.Bahuguna, Existence of solutions to neutral differential equations with deviated argument, Electronic Journal of Differential Equations, 27, (2008), 1-12.

[12] J.Changa, H.Liu, Existence of solutions for a class of neutral partial differential equations with nonlocal conditions in the $\alpha$-norm, Nonlinear Analysis, 71, (2009), 3759-3768.

[13] W. Desch, W. Schappacher, Linearized stability for nonlinear semigroups, in: A. Favini, E. Obrecht (Eds.), Differential Equations in Banach Spaces, in: Lecture Notes in Mathematics, Vol. 1223, Springer-Verlag, (1986), 6173. 
[14] K. Engel and D. Nagel, One-parameter Semigroups for Linear Evolution Equations, Graduate Texts in Mathematics, Springer-Verlag, 194, (2000).

[15] D.Henry, Geometric Theory of Semilinear Parabolic Partial Differential Equations, Springer-Verlag, Berlin/New York, 1989.

[16] K. Ezzinbi, X. Fu, K.Hilal, Existence and regularity in the $\alpha$-norm for some neutral partial differential equations with nonlocal conditions, Nonlinear Analysis, 67, (2007), 1613-1622.

[17] X. Fu, K. Ezzinbi, Existence of solutions for neutral functional evolution equations with nonlocal conditions, Nonlinear Analinear Analysis, Theory, Methods and Applications, 54 (2), (2003), 215-227.

[18] K. Ezzinbi, H. Megdiche, A. Rebey, Existence of solutions in the alpha-norm for partial differential equations of neutral type with finite delay, Electronic Journal of Differential Equations, 157, (2010), 1-12.

[19] J. K. Hale, Partial neutral functional differential equations, Rev. Roum. Math. Pures Appl., 39, 339-344, (1994).

[20] J. K. Hale, Coupled Oscillators on a Circle, Resen. Inst. Mat. Estat. Univ. Sao Paulo, 1, 441-457, (1994).

[21] J.K .Hale, J. Kato, Phase space for retarded equations with infinite delay, Funkcialaj Ekvacioj .21, (1978), 11-41.

[22] J.K. Hale, S. Verduyn-Lunel, Introduction to Functional Differential Equations, in: Applied Mathematical Sciences, Vol. 99, Springer-Verlag, New York, 1993.

[23] Y.Hino, S.Murakami, and T.Naito, Functional Differential Equations with Infinite Delay, Lectures Notes, Springer-Verlag, Vol. 1473, (1991).

[24] A. Pazy, Semigroups of Linear Operators and Application to Partial Differental Equation, Applied Mathematical Sciences, Springer-Verlag, New York, Vol. 44, (1983).

[25] B. N. Sadovskii, On a fixed point principle, Functional Analysis and its Applications, 1, (1967), 74-76.

[26] C. C. Travis and G. F. Webb, Existence and Stability for Partial Functional Differential Equations, Journal of Mathematical Analysis and Applications, 200, (1974), 395-419.

[27] C. C. Travis and G. F. Webb, Existence, stability, and compactness in the $\alpha$-norm for partial functional differential equations, Transaction of the American Mathematical Society, 240, (1978), 129-143. 
[28] C. C. Travis and G. F. Webb, Partial differential equations with deviating arguments in the time variable, Transactions of the American Mathematical Society, 56, (1976), $397-409$.

[29] J. Wu, Theory and Applications for Partial Functional Differential Function, Applied Mathematical Sciences, Springer-Verlag, Vol. 119, (1996).

[30] J. Wu and H. Xia, Self-sustained oscillations in a ring array of coupled lossless transmission lines, Journal of Differential Equations, 124, (1996), 247-278. 